\title{
Ollon-Villars - évolution d'une commune de la vallée du Rhône
}

Etude de géographie humaine

Alain Pichard

La commune d'Ollon est située sur le versant oriental de la cluse du Rhône. Du fond de la vallée, situé à $390 \mathrm{~m}$, elle s'étend vers le NE jusqu'au Chamossaire, $2112 \mathrm{~m}$, et vers l'E jusqu'au pied de la paroi des Diablerets. Son étendue couvre près de $60 \mathrm{~km} 2$. Ces vastes dimensions et le relief accidenté expliquent la grande variété des zones qui la composent.

Dans la région d'Ollon, la cluse du Rhône traverse une bande peu résistante de l'arc préalpin, qui du point de vue géologique correspond à une fenêtre dans laquelle apparaissent les nappes ultrahelvétiques. Les roches friables qui les composent gypse, corgneule, calcaires impurs, schistes, flysch - expliquent la rareté d'affleurements rocheux et le relief arrondi. Dans ces terrains, affouillables, les affluents du Rhône - Gryonne et Grande-Eau se sont fortement encaissés: arrivés dans la plaine, ils y ont construit de puissants cônes de déjection. Du milieu de la plaine émergent des collines de calcaire noir, les rochers de Saint-Triphon, dont l'origine est encore controversée.

Le glacier du Rhône aussi bien que les glaciers affluents locaux ont laissé de fortes traces dans le paysage: blocs erratiques, petits vallum morainiques (près d'Antagnes surtout) et banquettes glaciaires. Le vaste épaulement Villars-Chesières, à 1200 à $1300 \mathrm{~m}$ formé de sables est sans doute aussi d'origine morainique. Presque toute la région entre Ollon et Villars est tapissée de matériaux quaternaires.

Les sols cultivés sont de qualité très variable, mais ont presque tous en commun une forte proportion de calcaire. Près du Rhône, on trouve des sables, du limon et de la tourbe siliceuse, favorable au tabac. Plus haut, une bande de terre forte argilocalcaire, véritable terre à blé. Sur le cône de la Gryonne, des terres légères entrecoupées de bancs de gravier. Le bas du cône d'Ollon est composé de sables ou d'argiles légèrement graveleuses, alors que le haut est franchement caillouteux. Sur les versants, les sols pauvres du gypse alternent avec des bonnes terres argileuses d'origine glaciaire.

Les données sur le climat font défaut. Les vents sont peu fréquents, et peu violents, à l'exception du foehn en automne. Les hauts sont toujours bien arrosés, mais la plaine est relativement sèche $(930 \mathrm{~mm}$ par an de précipitations au Pont de Collombey). En été, le climat de la plaine est très chaud, alors que les courants ascendants raffraîchissent les hauts, provoquant souvent du brouillard. En hiver, la plaine rassemble l'air froid (mer de brouillard), mais sur les versants abrités, la saison est assez douce.

Vu les roches perméables du sous-sol, les sources sont rares. Le débit très variable de la Gryonne, et la nature friable du terrain en font un torrent redoutable, qui été corrigé à maintes reprises.

La commune d'Ollon est riche en forêts - $31 \%$ du territoire sont boisés. En gros, on peut distinguer quatre zones de végétation: aulne et frêne près du Rhône; pin sylvestre, chène pubescent et érable champêtre sur les versants gypseux; hêtre, mêlé au sapin et au sycomore entre 600 et $900 \mathrm{~m}$; résineux en prédominance dès $1000 \mathrm{~m}$, l'épicéa surtout.

Parmi les essences introduites artificiellement, citons le noyer, qui monte jusque vers $1000 \mathrm{~m}$ (au recensement de 1951, Ollon était la commune de Suisse la plus riche en noyers) et le châtaignier, qui ne prospère guère que dans les terrains morainiques d'Antagnes, et que le manque de soins et la maladie du chancre condamment à disparaître.

\section{Répartition et type de l'habitat}

Les versants sont peuplés jusque vers l'altitude de $1300 \mathrm{~m}$ et des localités s'échelonnent aux divers niveaux. La commune se divise en plusieurs étages correspondant à des ensembles économiques et aussi à des genres de vie divers. Autrefois on se contentait d'opposer plaine et montagne, aujourd'hui le développement de la station touristique de VillarsChesières oblige à distinguer trois zones:

- La "plaine» comprend le fond alluvial, les cônes de déjection - qui concentrent la majorité de l'habitat - ainsi que les premiers versants (Antagnes). Cette zone est avant tout agricole et viticole.

- La «station» englobe Chesières, Villars et Arveyes, bien que ce dernier village ne se soit pas autant développé que les deux autres. Elle vit presque exclusivement du tourisme.

- Entre ces deux zones se situe une bande intermédiaire $(600$ à $1000 \mathrm{~m})$ que les indigènes nomment les «Mi-Monts». C'est le domaine de l'agriculture de montagne. En dépit d'un genre de vie identique les Mi-Monts ne forment pas une unité cohérente, et la vieille division en «dizains» y a gardé son sens. 
Il n'y a guère de rapports entre Huémoz et le dizain de Panex qui comprend tout le versant de la Grande-eau; économiquement Huémoz regarde vers Villars, alors que le dizaine de Forchex, situé en contrebas, est orienté vers Ollon.

L'habitat est concentré, sans doute à cause de la rareté des sources. Les fermes isolées en plaine sont tout au plus une douzaine. Néanmoins on constate un foisonnement de petits écarts de 5 à 10 maisons. Ces minuscules écarts se trouvent surtout dans les Mi-Monts où ils occupent des replats d'origine glaciaire parfois larges d'une centaine de mètres seulement.

En plaine les inondations du Rhône ont longtemps repoussé la population contre les versants ${ }^{1}$. Le village de Saint-Triphon s'est réfugié sur le flanc d'un des rochers dans un site défensif. Ollon, au sommet du cône bénéficie d'une position climatique particulièrement abritée. Du centre marqué par l'église le village s'étale dans quatre directions sur les anciennes routes qui conduisaient à Aigle, Bex, Panex et Huémoz-Chesières. Ces quatre secteurs du village formaient autrefois des quartiers politiquement distincts. Ceux de la moitié $\mathrm{N}$ surprennent par leur aspect urbain: les maisons - habitations de vignerons en pierre et à plusieurs étages - se joutent, alors qu'écuries et granges sont rejetées vers l'extérieur. Une disposition analogue se retrouve à $\mathrm{Pa}$ nex ${ }^{2}$.
Dans les Mi-Monts les villages sont en général alignés le long d'une ou de deux rues perpendiculaires à la pente. Le cas le plus frappant est celui d'Antagnes: formé par une série de caves vigneronnes qui n'étaient à l'origine qu'un habitat temporaire, ce hameau s'étire au sommet du vignoble sur un kilomètre de longueur. A Antagnes le bois se mêle parfois à la pierre, plus haut les chalets prédominent. Autrefois concentrée, la maison du montagnard s'est dissociée dans la plupart des cas ${ }^{3}$. Le logement, agrandi par la dissociation ou par des adjonctions latérales, a pu accueillir des villégiants dans les premières années du tourisme.

En dépit de leur altitude Villars et Chesières ont toujours constitué un habitat permanent, aussi loin que remontent les sources historiques. Villars est mentionné dès 1400, Arveyes même en 13044. A Chesières le noyeau primitif, situé sur la route a été englobé dans la zone touristique; profondément modifié il est devenu un village-rue. A Villars en revanche les grands hôtels sont dispersés parmi des bosquets de sapins à quelque 60 mètres au-dessus du hameau. La route coupe la pente à mi-hauteur entre le village et les hôtels et c'est là, sur un tronçon de $100 \mathrm{~m}$ que s'est établi le centre commercial de Villars à maisons contiguës de style varié et fantaisiste. Le long de l'artère routière maisons et pensions s'échelonnent jusqu'à Chesières et Arveyes; autour de la gare un centre secondaire s'est formé.

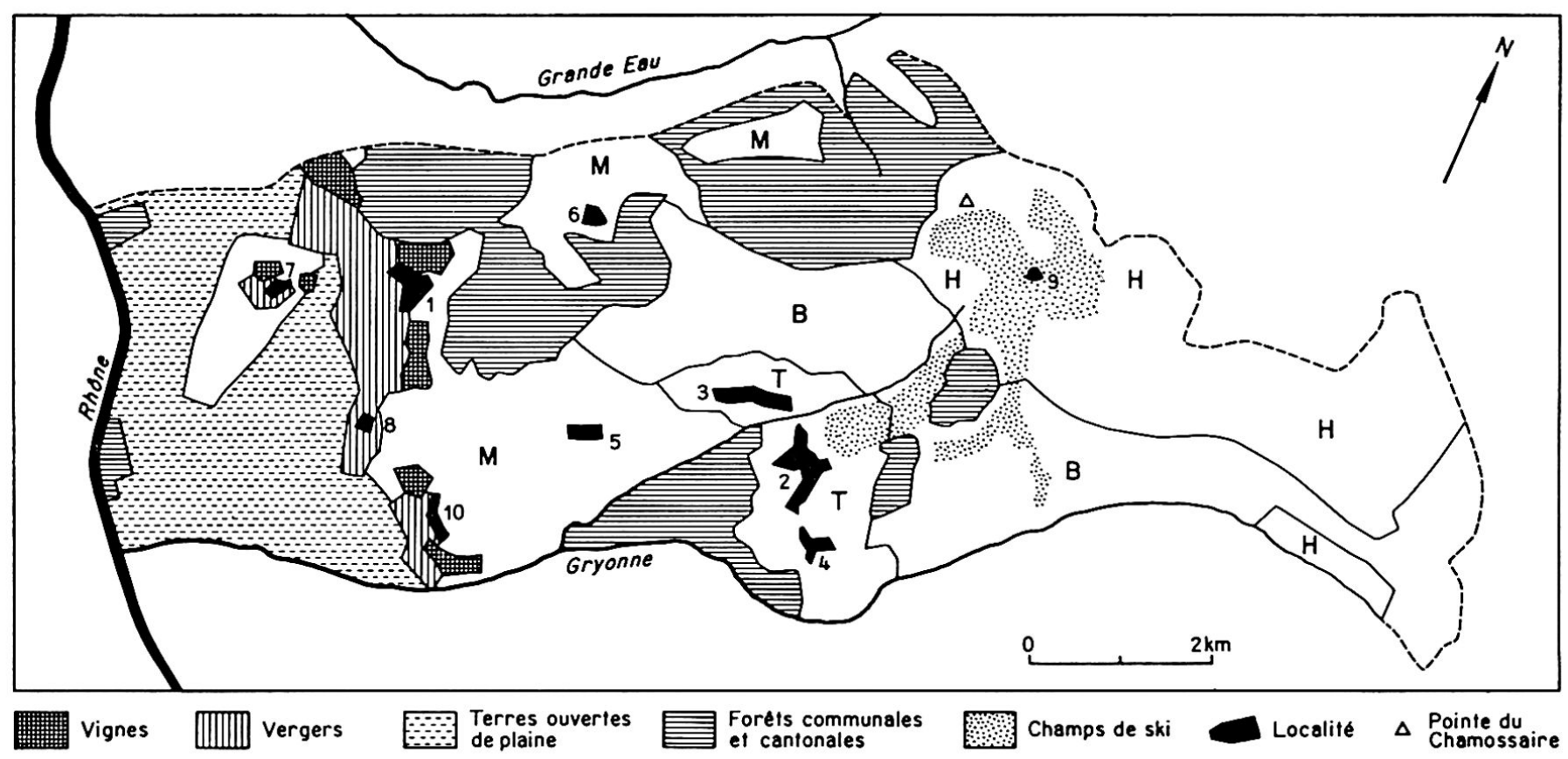

Figure 1. Utilisation du sol.

M Mi-Monts

$T$ Périmètres touristique Villars-Chesières-Arveyes

B «Basses montagnes»

$\mathrm{H}$ «Hautes montagnes» communales
1 Ollon

2 Villars

3 Chesières

4 Arveyes

5 Huémoz
6 Panex

7 Saint-Triphon-Village

8 Villy

9 Bretaye

10 Antagnes 
Ainsi l'habitat de Villars se caractérise par une dispersion extrème renforcée depuis quelques années par une multitude de petits chalets locatifs; ils occupent toute la conque et tendent à déborder en direction de Huémoz et de Bretaye.

\section{Démographie}

Il existe deux sources pour les données démographiques de la commune d'Ollon: d'une part les recensements fédéraux décennaux qui portent seulement sur l'ensemble de la commune, et depuis 1942 les recensements communaux annuels qui distinguent les différentes localités: mais les deux bureaux de police qui s'en occupent utilisent des critères différents, si bien que leurs résultats ne peuvent être ni additionnés ni comparés et doivent être considérés comme très approximatifs.

La population totale de la commune a assez régulièrement augmenté de 1900 à nos jours, exception faite de quelques périodes de stationnement dus probablement à l'exode rural et d'une baisse sensible entre 1930 et 1941 qu'il faut imputer à la crise économique d'une part et de l'autre à la guerre qui paralysa, du moins à ses débuts, une activité touristique déjà florissante.

L'évolution a cependant été variable selon les zones d'altitude, ainsi que le prouvent les chiffres communaux:

En plaine la population a diminué pendant la première moitié du siècle; depuis la guerre elle reprend lentement au chef-lieu:

$\begin{array}{lrrr} & 1900 & 1946 & 1966 \\ \text { Ollon } & 1199 & 868 & 1015 \\ \text { Saint-Triphon } & 525 & 424 & 410\end{array}$

Les.Mi-Monts se dépeuplent également; seul Huémoz, favorisé par la proximité de Villars-Chesières, réussit à rester stationnaire:

$\begin{array}{lrrr} & 1900 & 1946 & 1966 \\ \text { Huémoz } & 209 & 214 & 209 \\ \text { Dizain de Panex } & 246 & 195 & 145 \\ \text { Dizain de Forchex } & 217 & \pm 150 & 107\end{array}$

Pour l'ensemble de Villars-Chesières-Arveyes les chiffres varient énormément d'une année à l'autre. Selon la date du recensement, avant ou après le début de la saison touristique, les quelques 300 saisonniers sont compris ou exclus du total. L'ampleur des fluctuations peut dépasser de beaucoup le chiffre de 300 , ce qui prouve que de nombreux résidents ne s'installent à Villars que d'une manière passagère: il s'agit d'étrangers, car la population suisse reste singulièrement stable. En 1966, sur un millier d'étrangers, seul 108 possédaient une autorisation d'établissement (des Italiens pour la moitié, quelques Français et Anglais).

L'évolution à long terme de la station se manifeste nettement:

\section{Villars-Chesières-Arveyes}

1860: 71 ménages

1900: 522 habitants

1945 à 1950: entre 1500 et 1800 habitants, dont environ 1300 Suisses

1960 à 1966: entre 1800 et 2500 habitants, dont environ 1250 Suisses

Si le nombre de Suisses est resté plus ou moins constant - et ceci vaut pour toute la commune - la population indigène a pourtant diminué. $\mathrm{Si}$ nous supposons que la plupart des autochtones sont nés dans la commune śla maternité d'Aigle n'existe que depuis cinq ans), nous voyons que leur nombre s'est presque réduit de moitié en quarante ans. Il y a donc un exode rural très net. Il affecte non seulement les bourgeois d'Ollon, dont 2567 étaient établis hors de la commune en $1960^{5}$, mais également les descendants d'immigrés 6 : en effet le nombre de bourgeois résidents n'a pas baissé dans la même mesure que le nombre d'autochtones, et les naturalisations ne sont sans doute pas les seules responsables de ce phénomène.

En revanche les Vaudois non-bourgeois et surtout les Confédérés ont accru leur effectif jusque vers 1950, époque à laquelle les étrangers prirent la relève. Ces allogènes n'ont pas seulement été attirés par le tourisme. Si les Confédérés représentent le $43 \%$ de la population suisse de la station, ils constituent un tiers des habitants de la partie agricole et

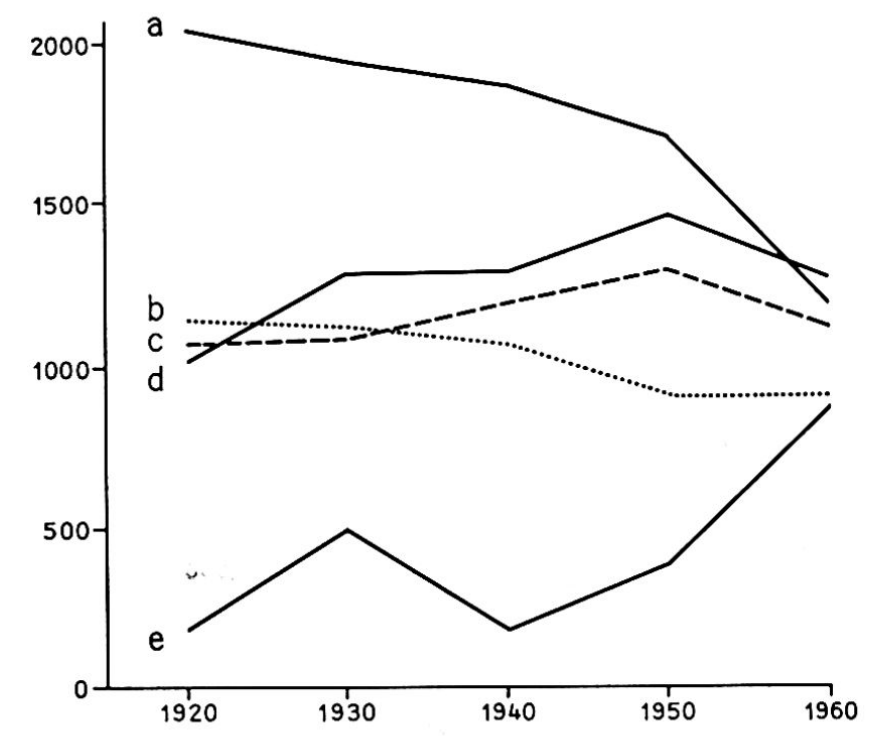

Figure 2. Origine de la population.
a) Nés dans la commune
b) Bourgeois
c) Autres Vaudois 
dans certains écarts des Mi-Monts ils sont même en majorité. Les cantons les mieux représentés sont Berne: $40 \%$ en 1950 et le Valais: $25 \%$. Les Bernois, immigrants de longue date ${ }^{7}$, sont souvent paysans et leur nombre tend à diminuer, alors que 100 nouveaux Valaisans se sont établis entre 1941 et 1950: quelques vignerons et surtout des employés d'hôtel. En résumé, la population autochtone diminue lentement, remplacée à mesure par des immigrants confédérés, alors que la population étrangère évolue d'une manière capricieuse, mais avec une tendance générale à l'augmentation.

Dans cette commune presque uniquement agricole et viticole à l'origine, les activités industrielles et surtout touristique ont pris un essor considérable, tandis que les activités agricoles se concentraient dans les mains d'un nombre toujours plus restraint de paysans.

\section{Population active}

\begin{tabular}{|c|c|c|c|}
\hline Secteurs & 1920 & 1941 & 1960 \\
\hline $\begin{array}{l}\text { Agriculture, } \\
\text { Viticulture }\end{array}$ & $45 \%$ & $35 \%$ & 19,5 \\
\hline Industrie & $22 \%$ & $25 \%$ & 28 \\
\hline $\begin{array}{l}\text { Commerce, trans- } \\
\text { ports, Hôtellerie }\end{array}$ & $15,5 \%$ & $19 \%$ & 33 \\
\hline Autres 8 & $17,5 \%$ & $21 \%$ & 19, \\
\hline
\end{tabular}

Les activités sont cependant très inégalement réparties suivant les zones d'altitude: la station touristique fournit plus de la moitié des emplois non-agri-

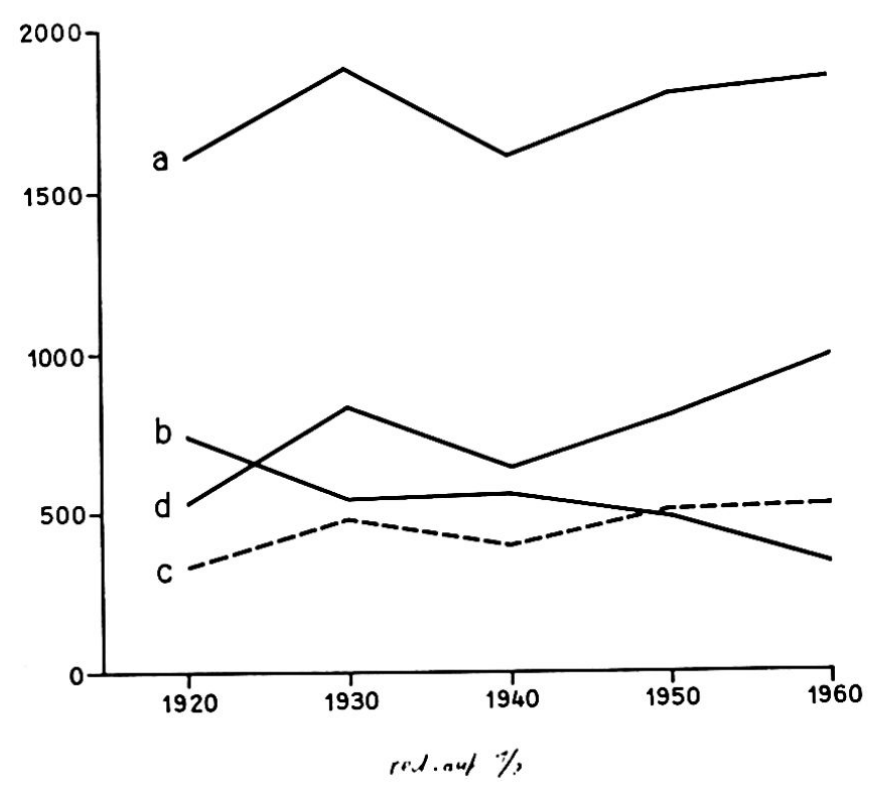

Figure 3. Activités.
a) Total des personnes actives
Secteurs:
b) Agriculture
c) Industrie
d) Autres

coles, car malgré ses 2000 habitants elle ne compte qu'une quinzaine d'exploitations paysannes, la plupart appartenant d'ailleurs à des vieux garçons.

En dehors de la station l'agriculture n'est pas aussi minoritaire qu'elle ne le paraît. Dans ce secteur les femmes ne sont pas considérées comme personnes actives, alors qu'elles le sont dans le secteur tertiaire. D'autre part, 257 personnes quittent quotidiennement la commune pour travailler au dehors 9 : il s'agit d'ouvriers et d'employés, et on peut supposer qu'ils n'habitent pas Villars-Chesières, trop éloignés des centres industriels et commerciaux de la plaine. Parmi les activités exercées sur place, l'agriculture et la viticulture gardent une bonne position dans toute la partie non-touristique de la commune.

Le fort afflux de personnes étrangères et les modifications intervenues dans la répartition professionnelle prouvent que la commune d'Ollon a subi une évolution intéressante qui n'a cependant pas été identique dans les trois zones; aussi devrons-nous en étudier séparément le développement. Mais auparavant il convient d'analyser le point de départ de cette évolution: l'ancienne économie traditionnelle qui explique ce fait curieux que vingt localités aussi différentes ne forment qu'une seule commune.

Jusque vers 1930 le fond de la plaine était marécageux, malsain, le cône de la Gryonne fréquemment inondé, aussi l'habitat se collait-il au versant et seules quelques zones de plaine particulièrement favorisées étaient mises en culture. L'économie traditionnelle d'Ollon est une économie de versant, plus orientée vers la montagne que vers le Rhône.

Les paysans surent tirer parti des sols variés et des divers étages de végétation qui composent le territoire communal. Bénéficiant en outre d'un climat très doux - le figuier, l'amendier et le mûrier ont poussé à Ollon - ils pouvaient se livrer à des cultures variées et complémentaires qui leur assuraient l'autarcie au point de vue alimentaire ${ }^{10}$.

Le paysage agraire comportait les niveaux suivants:

- Les marais du bord du Rhône, en flachère, fournissaient la litière. Les zones de plaine moins humides consistaient en pâturages ou en prés maigres.

- Dans la partie inférieure du cône d'Ollon et dans le secteur Villy-la Salaz s'étendaient les champs de blé, alors que le haut graveleux du cône d'Ollon, recouvert d'un verger très dense, produisait des pommes renommées sur les marchés de Lausanne et de Genève.

- La vigne occupait les premiers versants; au-dessus s'étendait la forêt, défrichée par endroits au profit du châtaignier et du noyer.

- Plus haut succédait le domaine des hameaux de montagne: prés et forêts, mais aussi des champs de céréales, de pommes de terre et de chanvre. 
- A 100 m environ au-dessus des localités supérieures commençait la zone des «basses montagnes", pâturages de printemps et d'automne, équivalents aux "mayens» valaisans et généralement entrecoupés de forêts. Les "hautes montagnes», audessus de $1700 \mathrm{~m}$, servaient de pâturage d'été11.

Seule la plaine a été profondément transformée; sur les pentes l'étagement subsiste encore aujourd'hui. Cependant il n'y a plus de champs en montagne et les arbres fruitiers sont en net recul.

Aussi variées qu'aient été les cultures et les travaux qu'elles exigeaient, il n'y avait pas à l'origine de spécialisation, chaque famille entendant suffire ellemême à ses besoins les plus divers. Le doyen Bridel écrivait: "Les habitants d'Ollon sont tour à tour dans l'année bergers, faneurs, moissonneurs et vignerons ${ }^{12}$." Il faut ajouter l'activité de bûcheron exercée en hiver. Toute famille paysanne possédait deux ou trois têtes de bétail et remuait entre la plaine et les basses montagnes, parfois avec des étapes intermédiaires; le système de la "grande montagne» adopté sur les pâturages d'été n'était pas généralisé dans les basses montagnes. Aussi le calendrier agricole était-il très chargé. Il semble cependant que dès le milieu du XIX ${ }^{\mathrm{e}}$ siècle les paysans d'Ollon aient accordé une importance particulière à l'activité viticole au point de négliger les cultures de plaine dont les produits souffraient de la concurrence étrangère ${ }^{13}$.

Ces activités impliquaient une dispersion de la propriété à tous les niveau de culture, favorisée par les communications relativement faciles sur le versant. Alors que le type d'exploitation s'est beaucoup modifié au cours du $\mathrm{XX}^{\mathbf{e}}$ siècle, le cadastre, plus résistant à l'évolution, conserve encore les traces de l'ancien état. Des montagnards ont des possessions en plaine et vice versa.

A l'origine les cas les plus fréquents étaient les suivants: Des gens de la plaine possédaient un pâturage dans les basses montagnes, avec un chalet et un peu de forêt.

Des montagnards possédaient en basse altitude des vergers, quelques châtaigniers, un peu de maïs et surtout un parchet de vigne pour leur usage personnel, accompagné d'une "cave» où ils logeaient pendant les travaux et pressaient et encavaient leur vin14. Les gens du versant de la Gryonne avaient leurs vignes à Antagnes - certains à Bex ou même sur le plateau de Chiètres - , ceux du versant de la Grande-Eau à Plan-d'Essert sur Ollon. Au cours des siècles de nombreux montagnards se sont établis en plaine, tout en conservant leurs propriétés du haut 15 .

Corollaire de la dispersion, le morcellement de la propriété foncière est encore actuellement la plaie de l'agriculture sur la commune d'Ollon, bien qu'il ait été fortement réduit en plaine par des remaniements:
Nombre de parcelles

par exploitation ${ }^{16}$

$13 \quad 11 \quad 7-8$

Surface moyenne par parcelle ${ }^{17} \quad 31 \mathrm{a} \quad 35 \mathrm{a} \quad 62 \mathrm{a}$

(En 1955: 1 à 3 parcelles par exemple à Aigle et Bex, 4 à 6 à Gryon.)

Ce morcellement est dû à l'ancienne coutume successorale du partage intégral, c'est-à-dire que les héritiers, au lieu de se répartir les parcelles entières entre eux, partageaient chaque parcelle en autant de parts qu'il y avait d'héritiers. Ainsi à moins d'arrangements spéciaux, le morcellement s'aggravait à chaque partage. Cette coutume s'explique par le relief accidenté et la diversité des sols. En effet, de parcelle à parcelle l'altitude, l'exposition et le caractère pédologique diffèrent tellement qu'il était impossible de comparer la valeur des terrains selon un critère commun.

Parfois on pratiquait l'indivision qui entravait enencore plus l'exploitation rationnelle. Ainsi en 1900 le village d'Antagnes comptait 130 propriétaires pour 40 maisons 18 .

Le morcellement de la propriété a empêché la constitution de grands domaines agricoles - les rares exceptions telles que l'abbaye de Salaz, ancienne possession de Saint-Maurice, appartiennent à des allogènes - en revanche tous les paysans sont propriétaires.

C'est peut-être pour cette raison que les terrains communaux, qui dans bien d'autres communes furent rachetés par de gros propriétaires, gardèrent leur importance à Ollon.

Le domaine communal comprend des pâturages et des forêts. Sur les 1900 ha boisés seuls 900 ha appartiennent à la commune. La grande forêt de Salins ( $385 \mathrm{ha}$ ) ainsi que les fonds de la Gryonne sont domaine cantonal: ces zones entourvent d'anciennes mines de sel et le gouvernement bernois se les appropria au XVII ${ }^{e}$ siècle afin de disposer du bois nécessaire à l'évaporation de l'eau salée. Après la révolution la propriété passa à l'Etat de Vaud en dépit des protestations de la commune ${ }^{19}$. Les forêts privées se situent essentiellement dans les zones de boisement très lâche et semblent n'avoir jamais servi qu'à l'usage privé des propriétaires.

La commune détient le quasi-monopole de l'estivage: en effet elle possède la totalité des "hautes montagnes" (à l'exception du petit pâturage de l'Arpille), soit 1091 ha divisés en plusieurs alpages distincts. Actuellement deux d'entre eux, Bretaye et Encex, ont gardé leur ancien statut de "commun". Toute personne domiciliée dans la commune peut utiliser ces alpages contre une taxe proportionnelle aux têtes de bétail inalpé. Comme les alpes sont trop vastes pour la commune, des allogènes sont acceptés contre une légère surtaxe $20 . \mathrm{La}$ commune prend à sa charge l'enclosure, la fumure 
et l'entretien des chemins, en échange les usagers consacrent un nombre fixe d'heures à épierrer, débroussailler et couper les herbes toxiques.

Chaque alpage comprend un grand nombre de chalets groupés, autrefois jusqu'à 80 . A l'origine un seul appartenait à la commune, les autres à des particuliers par droit de superficie. La municipalité devait fournir gratuitement le bois pour la construction et la réparation des chalets, en revanche elle possédait un droit de préemption dont elle a largement usé. L'estivage dure deux mois, juillet et août, la commune fixant le jour de l'inalpe. Les usagers s'unissaient autrefois en consortages nommés «mêles» et engageaient un vacheur en commun'1. Actuellement on ne trouve guère que des amodiateurs généralement domiciliés en plaine; parmi les paysans du bas ils sont les seuls qui aient maintenu l'habitude des déplacements saisonniers.

\section{L'aménagement de la plaine}

Deux initiatives ont permis la transformation de l'ancienne agriculture en lui mettant à disposition de nouvelles surfaces: l'assainissement de la plaine et l'extension des cultures imposée par le Plan Wahlen.

Les tentatives de bonifier les terrains marécageux remontent au $\mathrm{XIX}^{\mathbf{e}}$ siècle. Mais le Grand Canal construit à cet effet s'avéra incapable d'évacuer toutes les eaux souterraines, aussi fut-il approfondi de 1917 à 192722. En même temps la plaine du Bruet située entre les collines de Saint-Triphon et le cône d'Ollon fut assainie par drainage et l'on procéda à un remaniement parcellaire. Mais sur les bords du Rhône vernes et flachères s'adaptèrent à la baisse de la nappe phréatique et la zone resta à peu près improductive.

Le Plan Wahlen obligea la commune d'Ollon à augmenter ses terres ouvertes d'au moins 200 ha. Ce fut alors (1939 à 1941) qu'on entreprit définitivement la mise en valeur de la plaine par une série de mesures radicales: assainissements, défrichements, et remaniement parcellaire portant sur 804 ha et concernant 420 propriétaires, soit pratiquement toute la population de la plaine23.

La mise en culture des terrains défrichés fut contrôlée par des techniciens. Acide et peu fertile à l'origine, le mélange de sable et d'humus forestier est devenu après vingt-cinq ans d'assolement et de fumure, un sol favorable à toutes les grandes cultures.

Les bords du Rhône, en tant qu'anciennes forêts sont propriété de la commune qui y afferme trois domaines. Les anciennes flachères appartiennent à des paysans d'Ollon, Saint-Triphon et Villy; quelques rares propriétaires se sont établis sur leur parcelle.

\section{Les grandes cultures}

Le blé est la culture la plus répandue et chaque exploitation lui consacre au moins une sole. La surface emblavée a augmenté depuis la fin de la guerre, refoulant l'avoine, et ceci malgré les rendements relativement bas: 251\%2 qx/ha (période 1951 à 1960. District d'Yverdon: 271/2). Le blé souffre de la rouille et du sec, en revanche le poids à l'hectolitre dépasse la moyenne suisse de $2 \mathrm{~kg}$ ( $80 \mathrm{~kg}$ contre 78 ). Les terres calcaires d'Ollon ne sont pas de véritables "terres à blé» et ne permettent pas de cultiver cette céréale deux ans de suite sans risque de piétin. Aussi les cultures sarclées et fourragères ont-elles une large place dans les assolements.

L'intérêt pour la pomme de terre a cependant beaucoup diminué chez les agriculteurs. Cette culture représentait en effet une étape provisioire de la mise en valeur des terrains nouvellement défrichés encore hostiles aux céréales 24 . Près des villages les petits champs qui ne produisaient que pour l'auto-consommation ont été abandonnés. L'apparition de nouvelles maladies exigeant de nombreux traitements, une mécanisation compliquée et coûteuse et la difficulté de trouver des débouchés font que cette culture se limitera bientôt à quelques grandes exploitations.

Autre plante sarclée, à peu près équivalente dans les assolements, la betterave sucrière a pris la place de la pomme de terre. Autrefois contingentées, les surfaces et la production ont nettement augmenté depuis la création de la sucrerie de Frauenfeld (1964). Les rendements paraissent donc largement compenser le coût élevé des machines 25.

Les cultures fourragères sont variées: à la traditionnelle prairie artificielle s'ajoutent la betterave fourragère et de plus en plus le maïs subventionné en tant que céréale fourragère et destiné plus à l'en-

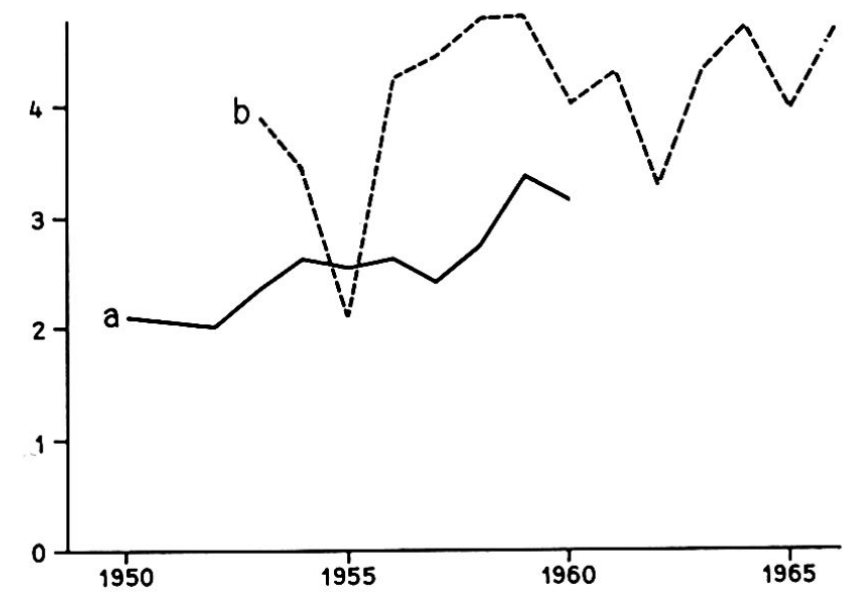

Figure 4. Rendement des cultures.

a) Céréales panifiables, en $t / h a$

b) Betterave sucrière, en dizaine de $t / h a$ 
silage qu'au séchage. Il n'y a plus guère de pâturages en plaine et le silo et les concentrés prennent une place prépondérante dans l'alimentation du bétail. Pour se procurer les concentrés à meilleur compte certains paysans ont repris la culture de l'orge.

\section{Cultures spéciales}

Autrefois Ollon produisait haricots et petits pois pour la fabrique de conserves de Saxon. Faute de main-d'œuvre cette activité intéressante a été abandonnée. Actuellement les cultures maraîchères se réduisent à quelques salades et oignons produits en gros.

Le tabac connaît un certain succès depuis la guerre. En raison du contingentement il ne s'agit que de surfaces restreintes, mais le tabac est après la vigne la culture qui procure le maximum de revenu par hectare, même s'il est, comme dans la plupart des cas, livré en vert ( \pm 6000 fr. net). Les terrains humides et sablonneux de la plaine alluviale, riches en matière organique lui conviennent. Planté fin mai, il se récolte en août. La société qui détient le monopole du tabac dans la région se charge des traitements antiparasitaires; les investissements en machines sont peu élevés. Le principal problème pour le planteur de tabac est de trouver la main-d'œuvre occasionnelle pour les quelques jours de la cueillette. Mais pour un petit propriétaire à famille nombreuse le tabac permet d'équilibrer le budget.

\section{Tabac 26}

Nombre de planteurs

Surface cultivée

Production, poids sec

$\begin{array}{crc}1950 & 1955 & 1960 \\ 11 & 11 & 15 \\ 497 \mathrm{a} & 448 \mathrm{a} & 711 \mathrm{a} \\ 11,6 \mathrm{t} & 10,4 \mathrm{t} & 13,1 \mathrm{t}\end{array}$

Le remaniement parcellaire des vergers d'Ollon a incité de nombreux propriétaires à abattre leurs arbres fruitiers. Ceux qui subsistent, âgés et négligés, ne produisent plus guère. En compensation la culture intensive des pommiers à basse tige a fait son apparition. Elle permet de mettre en valeur les terrains grossiers du cône ainsi que les bancs de gravier de la Gryonne. Bénéficiant d'un sol chaud sans pour autant souffrir d'une chaleur d'été excessive, ces pommes se conservent bien et trouvent des débouchés. Rares sont cependant ceux qui ont adopté cette culture; la majorité craint que les traitements intensifs n'usent un sol déjà bien pauvre.

Quant à la vigne elle fera l'objet d'un chapitre particulier. Au contraire de la plaine, aménagée récemment, le vignoble a son histoire, ses traditions, et les transformations dans l'agriculture n'ont sur lui qu'une faible influence.

\section{Les types d'exploitation}

Au lendemain de la guerre nous trouvons à Ollon des petits propriétaires-exploitants se livrant chacun intensément à une grande variété de cultures à la suite des exigences du Plan Wahlen. Cela impliquait un calendrier agricole chargé et beaucoup de maind'œuvre.

Mais le manque de main-d'œuvre à bon marché est le principal problème de l'après-guerre: il entraîne la mécanisation qui n'est rentable que sur de grandes surfaces. La petite exploitation est mise en question. Certes depuis longtemps les petits propriétaires ont dû louer du terrain agricole, généralement à d'anciens paysans devenus ouviers ${ }^{27}$, mais la demande de terrains et le prix de location augmentant ils doivent souvent se motoriser sans disposer de surface suffisantes. Bref, la mécanisation s'effectue plus rapidement que la concentration des exploitations:

\section{$1939 \quad 1955$}

$\begin{array}{lrl}\text { Exploitations } & 412 & 365 \\ \text { de plus de } 10 \text { ha } & 43=10 \% & 65=18 \% \\ \text { à terrain loué en majorité } & 97=24 \% & 82=22 \% \\ \text { Nombre de tracteurs } & 8 & 8328\end{array}$

Aussi la petite exploitation, pour ne pas devoir se procurer trop de machines diverses, tend-elle à se spécialiser dans une culture. Mais le sol pas particulièrement riche exige une certaine rotation des cultures. Entre le besoin de spécialisation et l'envie de conserver au sol un équilibre biologique éprouvé,

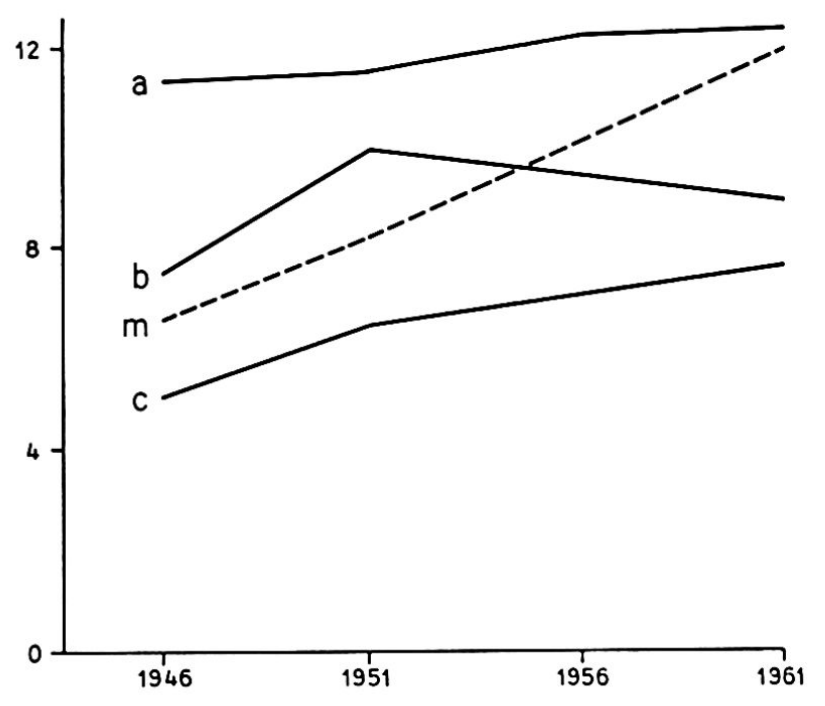

Figure 5. Cheptel.

a) Bovins non reproducteurs

b) Laitières

c) Porcs

en centaines

de têtes

m) Nombre de bovins par propriétaire 
l'agriculture de plaine hésite, tâtonne et se livre à des expériences variées. Mais ce n'est qu'après des années qu'on pourra tirer de ces essais, tous individuels, des conclusions générales.

Les paysans de Villy, Saint-Triphon et des fermes isolées sont généralement plus audacieux que ceux d'Ollon où la culture de la vigne absorbe une grande part de l'intérêt. De même les paysans venus du dehors ou simplement fils d'immigrés, ont plus d'initiative que les autochtones. Leurs exploitations - terres achetées et non héritées - sont les mieux regroupées et se prêtent le plus facilement à la rationalisation.

Quelques agriculteurs ont adopté la formule de la culture sans bétail fortement mécanisée. Ses avantages sont plus sociaux qu'économiques: elle supprime la servitude que représente l'entretien journalier du bétail, réduit les travaux manuels, permet l'exploitation d'un domaine moyen sans maind'œuvre étrangère. Dans l'assolement les cultures fourragères sont remplacées par la pomme de terre (1 ou 2 ans) suivie de betterave sucrière ou de cultures maraîchères. Pour compenser l'absence de fumier les cultures intercalcaires - moutarde, colza ou parfois même seigle d'automne - fournissent un engrais vert abondant.

A l'opposé nous trouvons des exploitations fondées avant tout sur le bétail et les fourrages, avec un peu de blé pour la paille. Ces exploitations nourrissent facilement une quinzaine de têtes, alors qu'autrefois trois têtes étaient un signe de richesse. En général la production de lait prédomine; mais si l'embouche exclusive reste une exception, rares sont les paysans qui n'engraissent pas quelques veaux de leur étable. Alors que ces dernières années le nombre de laitières diminue, la quantité de bovins destinés à la boucherie s'accroît.

Le possesseur de bétail établi en plaine prend de plus en plus distance de la montagne: il garde ses meilleures laitières en plaine durant l'été, allant parfois jusqu'à inalper seulement les genisses qu'il faut fortifier, et il préfère élever ses veaux plutôt que d'acheter du bétail montagnard 29 .

Entre la culture sans bétail et l'économie laitière toutes les transitions existent, et ceux qui adoptent les solutions extrêmes sont une minorité. Le paysan de plaine consacre généralement plus de soins aux cultures qu'au bétail, mais il estime que le terrain calcaire a besoin d'humus et que la fumure et la prairie artificielle lui sont indispensables. Aussi le bétail et les grandes cultures continuent-ils à coexister dans la plupart des entreprises, utilement complétées, selon les cas, par des cultures fruitières, du tabac ou même de l'ergot de seigle.

\section{La culture de la vigne}

Le type d'exploitation est essentiellement familial ${ }^{30}$. La propriété des machines est individuelle, sauf quelques exceptions. Tout récemment une expérience d'intégration horizontale a débuté. Un associé s'occupe des cultures, l'autres du bétail. Il ne s'agit pas de spécialisation, car chacun est capable de remplacer l'autre au besoin, mais d'un partage des responsabilités. L'avenir dira ce que vaut cette solution élégante.

La culture de la vigne s'est maintenue à Ollon sans devenir une monoculture comme sur les rives du Léman, mais sans perdre de son importance économique. Le territoire viticole de la commune - environ 80 ha - est confiné aux pentes et de ce fait son étendue ne s'est pas modifiée au cours de ce siècle.

Les sols sont variés et dans une certaine mesure complémentaire (l'association viticole a su exploiter cette variété en mélangeant les vins de quatre vignobles). Les terrains légers, qui exigent une fumure intense, ne donnent pas un vin très puissant, mais le raisin y mûrit bien. Le sous-sol gypseux donne au vin un goût particulier autrefois méprisé, mais il est frais en profondeur, et les vignes supportent facilement les périodes de sécheresse.

Le vignoble jouit d'une bonne exposition. Protégé des vents du nord, il est très printanier, mais craint les gelées tardives qu'entraîne la proximité des montagnes. La grêle, sans être rare, ne constitue pas une véritable menace, aussi n'existe-t-il pas d'organisation de lutte contre ce phénomène et les deux tiers des vignerons ne sont pas assurés. En automne le foehn accélère la maturité du raisin et les vendanges se font vers la mi-octobre.

Les cépages sont blancs en majorité (fendant, variété Saint-Joseph). Environ un vingtième du vignoble est planté en rouge, surtout des gamays. Les hybrides-producteurs-directs ont disparu. On laisse généralement les vignes jusqu'à un âge avancé: 20 à 22 ans. Ceci nuit au rendement qui est d'environ $4500 \mathrm{l} /$ ha en moyenne.

On compte environ 220 propriétaires-exploitants pour une superficie de 79 ha, soit une moyenne de 35 ares par exploitation, ce qui est très peu ${ }^{31}$. Il convient cependant de distinguer différents types d'exploitation:

- Les vignerons purs, à plein temps, sont moins de dix. Alors qu'à Aigle et Yvorne de nombreux paysans-vignerons ont abandonné la campagne, cette spécialisation n'a pas eu lieu à Ollon, la viticulture y étant moins rentable. 
- Les exploitations mixtes forment la majorité (50 à $60 \%$ ). Comme le tabac, la vigne est le support de la petite entreprise agricole et familiale grâce à ses rendements complémentaires à ceux de l'agriculture. Les années sèches, alors que les champs produisent peu, le raisin se vend au prix fort ${ }^{32}$. En revanche les fortes fluctuations des revenus viticoles sont contrebalancés par la relative stabilité des prix agricoles.

- Le tiers des vignerons sont des ouvriers de la plaine qui tout en travaillant à Monthey, Aigle ou Bex, s'occupent durant leurs heures libres de quelques perches de vigne, ceci autant pour leur fierté personnelle que pour les gains appréciables qu'ils en retirent. L'introduction dans l'industrie de la semaine de cinq jours a beaucoup favorisé cette activité accessoire; certaines opérations, tel le sulfatage, peuvent à la rigueur se faire le soir ou tôt le matin $\mathrm{Au}$ contraire de l'agriculture la vigne n'exige pas d'outillage compliqué ni de vastes locaux.

- A ces propriétaires domicilés en plaine il faut ajouter environ 35 montagnards qui ont gardé leurs vignes et leurs caves à Antagnes et Plan-d'Essert, également pour des raisons tant psychologiques qu'économiques. Parmi ceux de Villars-Chesières on trouve également des non-paysans: un facteur, un blanchisseur, un employé du chemin de fer. La vigne est un des rares liens économiques qui unissent la plaine et la «station», car ces propriétaires n'encavent plus, mais sont membres de l'association viticole d'Ollon.

Non seulement les exploitations sont petites, mais elles sont extrêmement morcelées. Il y a quelques années Antagnes battait le record cantonal avec des perchets de 2 à 5 perches $\left(20\right.$ à $\left.45 \mathrm{~m}^{2}\right)$. Les parcelles de 3 à 4 ares sont fréquentes. Le vignoble n'a jamais été remanié, chemins et canalisations font défaut. En conséquence la valeur des terrains viticoles est dérisoire 33 . Toutefois comme le nombre d'exploitants diminue (vieillards décédés, montagnards et gros paysans renonçant à la vigne par manque de main-d'œuvre) des parcelles se vendent et une lente concentration se dessine, le plus souvent au bénéfice de gens du dehors: vignerons valaisans et gros propriétaires d'Aigle.

Aux inconvénients de la petite propriété morcelée les vignerons ont pallié par une organisation communautaire.

L'Association viticole d'Ollon est parmi les plus anciennes du canton: elle s'avéra très tôt comme nécessaire vu le manque de caves individuelles ${ }^{34}$. L'usage de partager les parcelles entre héritiers ne pouvait s'appliquer aux caves et les propriétaires hésitaient à en construire sur des parcelles si infimes. Aussi beaucoup de vignerons devaient-ils vendre leur récolte à peine vendangée aux cafetiers et marchands de vin qui leur imposaient les prix du moment.

En 1906 les prix furent particulièrement bas et quelques vignerons décidèrent de louer une cave en commun. Ainsi naquit l'Association viticole qui de 15 membres au début passa progressivement à 215 en 1966, englobant désormais presque tous les viticulteurs de la commune. Après s'être constitué une clientèle dans le rayon local, elle put construire en 1934 ses propres caves, dont la capacité atteint actuellement $750000 \mathbf{1}^{35}$.

Traitant le vin en grosses quantités, mais avec l'aide d'un caviste spécialisé, elle réussit à lui conférer la qualité. Autrefois le vin d'Ollon, très mal payé, était revendu par les marchands sous l'étiquette d'Aigle. Le contrôle des caves, dès 1946, empêcha cette pratique. Mais la demande d' "Aigle» dépassant l'offre, Ollon fut englobé dans l'aire d'appellation Aigle-Yvorne à 49/51 ${ }^{\mathrm{c}}$ (c. -à.-d. qu'un mélange de $49 \%$ d'Ollon et de $51 \%$ d'Aigle peut-être vendu sous le nom d'Aigle et les prix de l' «Ollon» furent revalorisés: ils se situent à environ 20 ct. au-dessous de l'«Aigle».

Chaque année l'association viticole vend environ 1800001 (de 40 à $70 \%$ du total) aux détaillants sous le nom d'Ollon, le reste est livré aux grossistes. Les clients de l'association sont avant tout les restaurateurs de la commune - la station est un bon débouché - et des Ormonts; elle livre également à la région Montreux-Lausanne et dans certaines parties de la Suisse allemande où 1»Ollon» s'est fait un renom.

L'Association compte créer des installations pour l'encavage du rouge. Jusqu'à présent les rares propriétaires de cépages rouges possédaient leur propre pressoir.

Par son morcellement et la petitesse des exploitations, le vignoble d'Ollon forme contraste avec les terrains agricoles remaniés du fond de la vallée. Il représente l'élément conservateur dans l'économie de la plaine. L'association viticole cependant, en rationnalisant la vente, a permis de conserver la culture de la vigne dans sa forme ancestrale: comme complément à une autre activité, qu'elle soit agricole ou industrielle.

$\begin{array}{lrrrc}\text { Vignes } & 1951 & 1956 & 1961 & 1951-1963 \\ \text { Production hl } & 4580 & 1990 & 5160 & 3535 \\ \text { Rendement hl/ha } & 59 & 25 & 65 & 45\end{array}$


Ollon n'a jamais connu sur son territoire de grandes entreprises industrielles au sens strict, en revanche les industries extractives y ont toujours eu une certaine importance.

Les mines de sel qui attirèrent dans la région beaucoup d'immigrants bernois au XVII ${ }^{e}$ siècle, ne jouent plus un grand rôle économique. L'ancienne saline près de Panex et les mines de Chesières, Arveyes et Pallueyres sont désaffectées. Les mines de Bex elles-mêmes, qui ont longtemps procuré du travail aux gens d'Antagnes et des environs n'ont actuellement qu'un seul employé domicilié sur la commune d'Ollon.

Des carrières de gypse prospères existaient à Villy et à Ollon jusqu'au début du siècle, mais la GypseUnion de Bex les racheta et en suspendit l'exploitation. Actuellement seules subsistent deux des trois carrières de marbre de Saint-Triphon, encore que leur importance ait beaucoup diminué. Il y a soixante ans elles employaient 150 à 180 ouvriers $^{36}$, et tout habitant de Saint-Triphon se fût senti déshonoré s'il n'eût pas possédé sa maîtrise de tailleur de pierres. Aujourd'hui les carrières emploient 20 personnes, saisonniers compris, et faute de maind'œuvre l'exploitation de la pierre de taille a été abandonnée; le marbre concassé fournit soit du gravier pour le ballast des chemins de fer, soit des gravillons pour revêtements de chaussée, aussi les principaux clients sont-ils les CFF et l'Etat de Vaud. La gare de Saint-Triphon expédie journellement 400 à $500 \mathrm{t}$ de chaille.

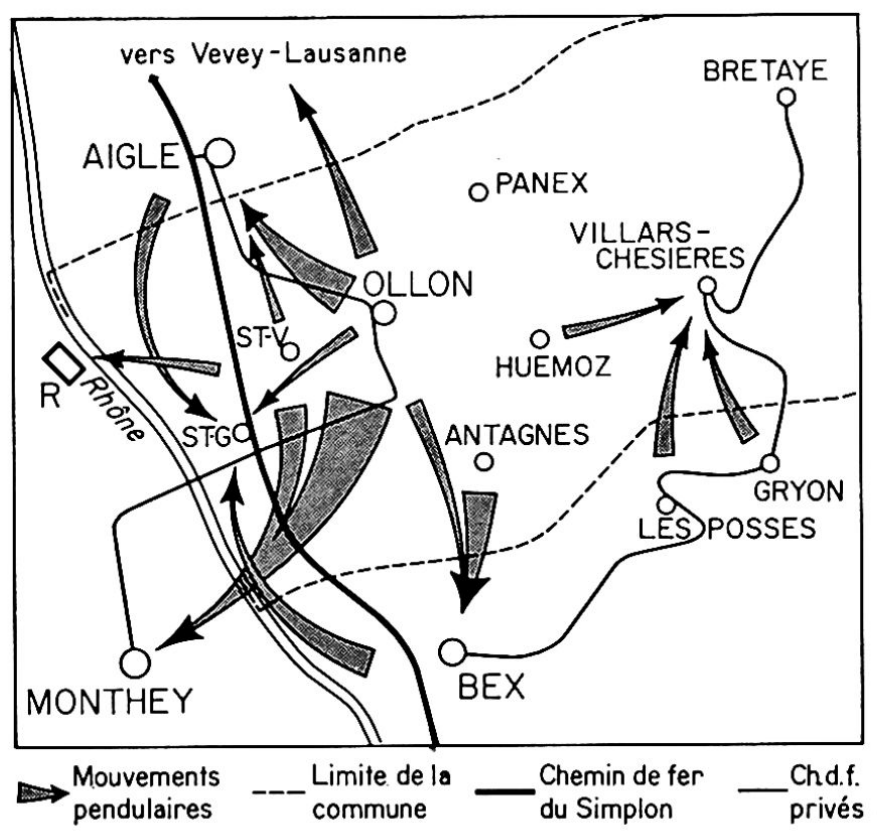

Figure 6. Mouvements pendulaires des travailleurs. ST-V Saint Triphon-Village, ST-G Saint-TriphonGare
C'est relativement peu de chose comparé aux quelque 200 wagons d'essence qui en partent chaque jour vers le plateau suisse ou l'Autriche, depuis qu'en 1963 Saint-Triphon est devenu la gare de triage des raffineries de Collombey. Elle comprend désormais $6 \mathrm{~km}$ de voies et emploie une vingtaine de personnes pour la plupart logés en dehors de la commune.

A part cela l'implantation des raffineries n'a guère eu de répercussions sur l'économie de la commune d'Ollon, sinon que quelques saisonniers se sont installés à Saint-Triphon et quelques cadres à Ollon.

Le chef-lieu n'a jamais cherché à s'industrialiser. Lors de la construction du chemin de fer du JuraSimplon, un projet visant à faire passer le tracé à l'E de Saint-Triphon, à proximité du village d'Ollon, fut abandonné37. Cinquante ans plus tard une ligne à voie étroite reliant Aigle à Monthey vint desservir Ollon qui depuis lors est nettement axé sur ces deux villes: Aigle est le centre administratif (bureaux, banques, hôpital, écoles), mais sur le plan commercial il est quelque peu supplanté par Monthey qui bénéficie de sa foire, de son marché bien achalandé et de prix relativement plus bas.

Aussi est-ce dans ces deux centres que travaillent la majorité des gens d'Ollon qui ont abandonné la campagne. On a certes décelé un exode rural pendant la première moitié du siècle, mais un grand nombre d'anciens paysans ont conservé leur domicile à Ollon et se déplacent quotidiennement. Monthey et en particulier la succursale de la CIBA absorbent environ 60 ouvriers et employés 38 . A Aigle, à l'exception de la fabrique de balanciers qui emploie un personnel à peu près exclusivement féminin et des constructions métalliques implantées récemment, ce sont de petites firmes locales, industrielles ou commerciales, qui emploient une ou deux personnes d'Ollon. Bex bien fournie en industries, englobe Antagnes dans sa sphère d'attraction, alors qu'à Ollon mème son influence est faible du fait du manque de communications. Quelques migrants journaliers poussent jusqu'à Vevey39.

Ainsi Ollon est un village riche en ouvriers. Le type du paysan-ouvrier possesseur de deux ou trois têtes de bétail, s'il paraît avoir existé, a désormais totalement disparu, seul subsiste l'ouvrier-viticulteur.

A l'exode rural s'est substitué depuis quelques années un mouvement inverse: des personnes travaillant dans les centres industriels, attirés par la position abritée et ensoleillée d'Ollon, par sa position surélevée par rapport à la plaine, se font construire une villa dans les vergers en contrebas du village. $\mathrm{Ce}$ sont le plus souvent des citadins d'Aigle ou des cadres de Monthey: cette ville a relativement peu 
de soleil et, conséquence de l'industrialisation rapide, le terrain y est très cher. Quelques-uns de ces cadres, Suisses-allemands et protestants, ont choisi de s'établir à Ollon pour des raisons confessionnelles. Les nouvelles maisons ont déjà atteint le chiffre de 30 et tout laisse supposer qu'il s'accroîtra encore.

Les gens d'Ollon sont bien conscients des atouts naturels de leur village et sa "vocation» de zone résidentielle n'est guère mise en question. En effet les nouvelles villas occupent les sols les plus grossiers et les moins fertiles du cône où même les arbres fruitiers ne rendent actuellement plus grand-chose. Aussi le remaniement parcellaire des vergers entrepris en 1960 a-t-il été combiné avec l'établissement d'un plan d'extension et la création l'infrastructures. La partie supérieure du cône constitue la zone à bâtir, la partie inférieure la zone de protection agricole, la zone agricole proprement dite se situant en dehors du cône. Ainsi, si les constructions continuent à foisonner, les cultures seront-elles finalement limitées aux terrains strictement plats. Dans ce cas Villy et Saint-Triphon pourraient fort bien supplanter le chef-lieu en tant que centre agricole, Ollon devenant les «beaux quartiers» de la région industrielle de la cluse, auxquels seule l'activité vigneronne - qui ne risque pas de disparaître de sitôt - conserverait un aspect paysan.

\section{Les débuts du tourisme}

Villars était le plus petit des dizaines et ne possédait même pas de pinte, lorsque vers 1830 un colonel en retraite acheta un chalet au-dessus du village et y aménagea quelques chambres qu'il eut l'idée de louer à des estivants. Plus tard une famille de Chesières logea une dizaine de personnes dans sa maison, puis en louant des chambres aux voisins elle put augmenter sa clientèle. En 1856 le colonel construisait un petit hôtel dit "Chalet de Villars", ouvert l'été seulement; sa clientèle, d'abord suisse, se recruta ensuite parmi les Français et Anglais amateurs de calme alpestre. Après l'ouverture de la route en 1867 les établissements hôteliers se multiplièrent. Leurs fondateurs - à l'exception d'un notaire de Chesières qui ouvrit le premier hôtel de son village - furent des personnes étrangères à la commune: un boulanger d'Aigle, un Ormonan, un industriel Alsacien. La station prit un essor rapide. Vers 1900 on dénombre 1100 lits - 790 à Villars, 390 à Chesières42. En 1913 la construction du VillarsPalace, grand-hôtel de luxe, vint confirmer le succès de la station.

$\mathrm{Si}$ beaucoup de causes de ce succès nous échappent, on peut pourtant affirmer que les facteurs purement géographiques ont joué un rôle important.
Facteurs géographiques: situation, site et climat

Villars a profité de la proximité de la route du Simplon, grande voie internationale. Dès 1857 le chemin de fer reliait Villeneuve à Bex. Quatre ans plus tard ce tronçon était raccordé à Lausanne et au réseau européen. Lorsque le tunnel du Simplon fut percé, la station s'était déjà solidement établie. Dans cette axe NO-SE, ouvert sur la France et l'Angleterre, Villars se vante d'être la station d'hiver la plus proche de Paris par la rapidité des communications: actuellement en chemin de fer neuf heures de nuit, huit de jour, sept en TEE.

Mais avant d'acquérir une renommée internationale Villars a certainement bénéficié du voisinage de la célèbre station hôtelière de Montreux. Peutêtre était-il à l'origine une sorte de résidence d'été pour les hôtes du bord du lac.

Villars doit une partie de sa réputation à son site. Terrain assez plat, propice aux promenades et aux sports, il surplombe néanmoins la plaine de $800 \mathrm{~m}$. Avant la vogue du ski de printemps on considérait son altitude - $1300 \mathrm{~m}$ - comme idéale pour un séjour en montagne. Enfin il profite d'un panorama exceptionnel qui englobe, outre les fameuses Dentsdu-Midi, le massif du Mont-Blanc et la barrière imposante des Hautes-Alpes calcaires. A Villars les montagnes sont assez proches pour impressionner, pas assez pour donner un sentiment d'oppression.

Les désavantages climatiques (brouillard en été) sont compensés par l'absence de vent, la douceur de l'hiver et la fraîcheur de l'été, mais surtout par sa forte insolation. La durée moyenne de l'insolation possible à Villars est de douze heures et demie pour les trois mois d'été et de huit heures et demie pour les trois mois l'hiver (à Aigle les chiffres correspondants sont onze heures trois quarts en été, sept heures et demie en hiver). Au cœur de l'hiver le touriste peut encore compter sur un minimum de sept heures de soleil.

\section{Les infrastructures}

Depuis longtemps une route pavée mais excessivement raide reliait les montagnes d'Ollon au cheflieu. La route actuelle fut achevée en 1867. Les promoteurs du tourisme sont très vite intervenus pour rendre commode l'accès à Villars. L'ouverture de la route amena l'installation d'un bureau de poste, puis d'un service de diligences remplacées l'hiver par un traîneau. Actuellement une voiture postale relie Ollon à Chesières, mais ne sert guère qu'au trafic indigène, car le chemin de fer draine tout le trafic touristique.

En 1901 déjà le chemin de fer avait atteint Villars, 
en 1906 Chesières que relie à Villars un nouveau pont sur la Gryonne: désormais ces deux localités, autrefois séparées par un profond ravin, tendront à former un seul ensemble.

En matière d'approvisionnement en eau Villars est favorisé. La conque est assez riche en eau et à l'origine chaque hôtel possédait sa propre source. Depuis 1913 la source communale du Poutet avec son fort débit et son altitude élevée a permis le développement de la station et en particulier la construction de nombreux chalets jusqu'au-dessus de $1400 \mathrm{~m}$. Ce n'est que depuis quelques années que les ressources du Poutet commencent à s'avérer insuffisantes au gros de la saison d'été.

\section{Le tourisme d'hiver}

La construction du chemin de fer permit à la station d'envisager une activité touristique également pendant la saison froide. Une société de développement se constitua et lança en 1905 à 1906 la première saison d'hiver. A l'origine les plaisirs de la neige consistaient en de longues promenades en traîneaux, guidés par des paysans de l'endroit, et en parties de luge. Les bobsleighs descendaient sur la route jusqu'à Ollon et leur remorquage au retour procurait quelques bénéfices aux indigènes. Le ski ne s'imposa que peu à peu, d'abord sur le plateau de Villars, puis en altitude. Le chemin de fer sur le Chamossaire, projeté vers 1911 par la société du Bex-Gryon-Villars devait avant tout attirer les amateurs de précipices et de vues grandioses: mais la guerre interrompit la construction à la hauteur de Bretaye. A défaut de panorama les promoteurs misèrent sur les champs de neige. Bretaye $(1800 \mathrm{~m})$ a l'avantage d'un bon ensoleillement même lorsque Villars se trouve dans la mer de brouillard. Les prospectus des années 30 parlent déjà de Bretaye comme du paradis des skieurs. Les champs de neige de Villars servirent désormais aux élèves de l'école de ski. Avec ses 40 moniteurs celle-ci représente aujourd'hui un facteur important dans l'économie de la station 43 .

Villars a toujours su se mettre au goût du jour et adopter très vite les innovations sportives (p. ex. le golf et la piscine et plus récemment la patinoire artificielle), d'où son succès. Aussi s'intéressa-t-il de bonne heure aux monte-pentes. Le fait que les montagnes de Bretaye sont propriété communale a sans doute facilité leur implantation, la municipalité se bornant à exiger que le personnel des téléskis fût pris dans la commune. La société des téleskis obtint au cours des années diverses concessions.

En 1942 , on comptait déjà environ $20 \mathrm{~km}$ de pistes de degrés de difficulté variés (pente moyenne allant de $9 \%$ à $24 \%$ ). Après la création d'une télécabine aboutissant au Roc-d'Orsay, contrefort du Chamossaire $(1959 \mathrm{~m})$ et un raccordement par un système de pistes et de monte-pentes avec la station de la Barboleusaz, les champs de ski de Bretaye se sont élargi vers le $\mathrm{NO}$ et le SE. Actuellement ils comptent 12 téléskis et une quarantaine de kilomètres de pistes.

Bretaye n'a pas que des avantages. La dénivellation des pistes est faible comparée à celles du Valais par exemple: au maximum $800 \mathrm{~m}$ du Chamossaire à Villars. De nos jours le ski de printemps est à la mode mais en mars déjà la neige tassée disparaît par endroits sur les pentes ensoleillées de Bretaye et surtout sur les pistes qui descendent à Villars. Parfois même à Noël la neige fait défaut. Les pistes aménagées sur les revers sont peu fréquentées: les skieurs exigent à la fois le soleil et la neige et sous cet aspect Bretaye est nettement trop bas. Aussi Villars compte-t-il sur la route du col de la Croix un projet vieux de cent ans actuellement en cours de réalisation. Elle le reliera à la station des Diablerets

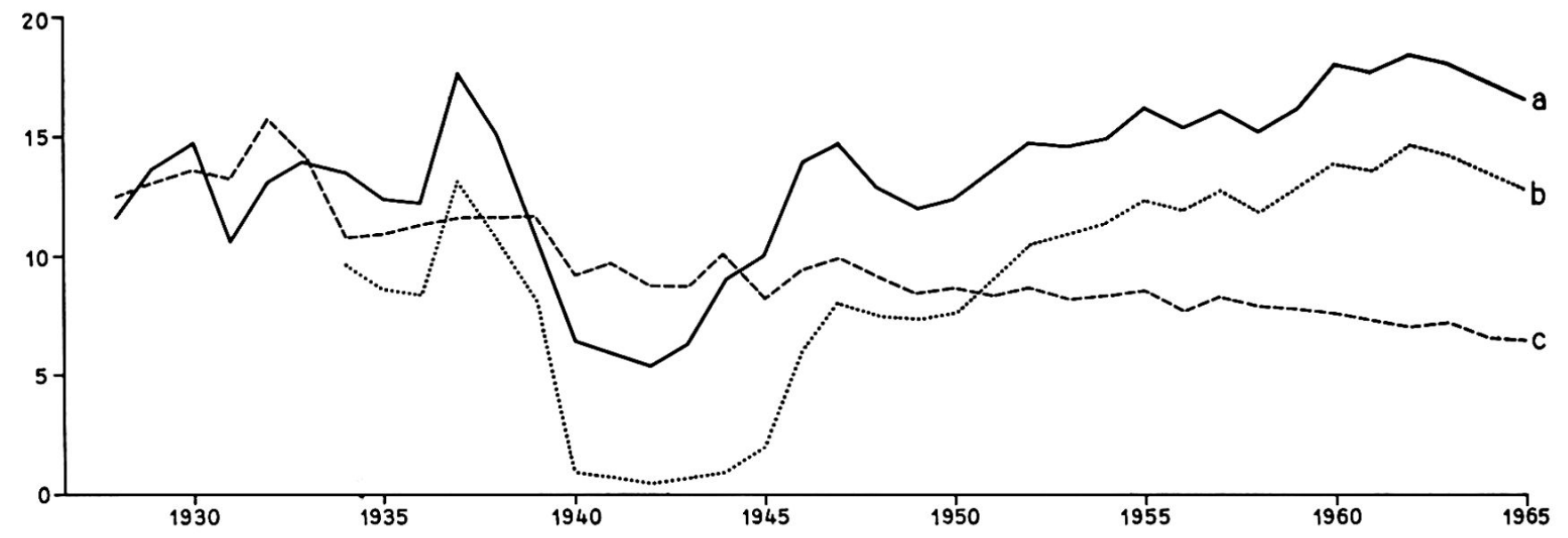

Figure 7. Tourisme hôtelier à Villars-Chesières-Arveyes.

$\left.\begin{array}{l}\text { a) Nuitées totales } \\ \text { b) Nuitées des étrangers }\end{array}\right\}$ en dizaine de milliers

c) Durée moyenne de séjour, en jours 
qui possède ses champs de ski à $3000 \mathrm{~m}$ sur le glacier du même nom. Les promoteurs de Villars et de Gryon réunis envisagent une télécabine menant au Pas-de-Cheville, col ouvert sur le Valais central. Ainsi peut-être Villars deviendra-t-il le centre résidentiel d'une vaste région aménagée pour les sports d'hiver et d'été.

\section{Les diverses formes de tourisme et leur évolution}

Le séjour en hôtels ou pensions a été à l'origine l'unique forme de tourisme et l'ouverture de nouveaux établissements hôteliers s'est poursuivie jusque vers 1930 . Le nombre de lits a atteint le chiffre exclusif de 1750 en 1932, depuis il s'est constamment réduit sauf quelques légères augmentations provisoires à la suite des bonnes saisons (voir graphiques). La majorité de la clientèle a toujours consisté en étrangers, sauf pendant la guerre où les Suisses bloqués dans leur propre pays les ont partiellement remplacés. La courbe des nuitées reflète la crise de 1929, la guerre de 1939 à 1945 et également une période critique en 1948 à 1950, due peut-être à l'insécurité générale (Berlin, Corée), vite compensée par un afflux massif d'étrangers dans les années suivantes. Depuis 1962 cependant les nuitées diminuent en flêche. Cette crise peut s'expliquer par les conditions économiques du moment, mais peut-être est-elle la conséquence de profonds changements dans la manière de villégier.

En effet la station de Villars s'est développée à une époque où la villégiature était réservée à un nombre limité de privilégiés. Une clientèle aussi riche en temps qu'en argent faisait à la montagne des cures de plusieurs mois.

Villars est encore maintenant une station relativement luxueuse. Voici pour 1958 la répartition des nuitées selon les trois catégories d'hôtels que distingue P. Defert45:

Hébergement de plus de fr. 18.50: $\quad 35,9 \%$

Hébergement de fr. 12.50 à fr. 18.50: $61,6 \%$

Hébergement de moins de fr. 12.50: $\quad 2,5 \%$

Mais entre les deux guerres le tourisme s'est vulgarisé et »la notion de voyage a supplanté celle de séjour»46. Le temps disponible pour la villégiature se réduit, aussi la durée moyenne de séjour diminuet-elle constamment (voir graphique). En hiver les hôtels ne sont pleins qu'entre Noël et Nouvel-An. Néanmoins le total des nuitées est plus elevé en hiver (1965 à 1966: 81 000) qu'en été (1966: 75 000), lorsque la concurrence des stations balnéaires se fait sentir. Même la durée de séjour est plus courte en été: 5,7 jours en 1964 sur une moyenne annuelle de 6,5.

La composition nationale de la clientèle s'est également modifiée: à l'origine les Anglais prédomi- naient; en fonction d'un séjour prolongé le long voyage leur importait peu. Or les fortunes anglaises ont beaucoup souffert de la guerre. Ce sont les Français, moins éloignés, qui ont pris la relève. Les Belges viennent volontiers à Villars pour raison de santé. Les Italiens commencent à affluer en été et les hôteliers comptent se créer une nouvelle clientèle en Espagne; en outre ils espèrent que la route du col de la Croix, prolongement du Pillon leur amènera un nombre accru de Confédérés et d'Allemands.

Bon nombre de touristes cependant mettent en question l'institution même de l'hôtel. L'étiquette n'est plus de mise. A mesure que la durée de séjour s'écourte, les villégiants ont besoin de plus de liberté et de non-conformisme: d'où la vogue des chalets de vacances.

L'usage de louer des chalets remonte jusqu'au siècle passé, mais les locataires formaient une clientèle particulière, peu exigeante et aimant la rusticité. Déjà avant la deuxième guerre certains particuliers se firent construire des logements de vacances, et depuis une dizaine d'années de nombreuses sociétés immobilières se sont spécialisées dans la construction de chalets standardisés «tout confort». Depuis lors le prix du terrain atteint des sommes élevées et les spéculations se multiplient. Certaines sociétés se bornent à acheter le terrain, à y installer les infrastructures (eau, gaz, téléphone, etc.) et à le vendre en parcelles isolées. Un tel lotissement peut comporter plus de cent parcelles.

Les chalets ne restent que rarement propriété de la société immobilière: celle-ci les vend aux détenteurs de capitaux en quête de placement, depuis 1964 surtout à des étrangers ${ }^{47}$. Ces nouveaux propriétaires viennent en séjour durant les vacances; pendant le reste de l'année ils louent le chalet par l'intermédiaire d'une gérance: seuls les mois d'octobre et novembre sont véritablement une saison morte pou les chalets. Propriétaires et locataires ne sont généralement pas des nouveaux venus à Villars: pour la plupart ils ont pris goût à la station lors d'un séjour en hôtel. Ainsi la clientèle déserte peu à peu ces établissements au profit des chalets.

C'est lors de l'apogée du tourisme hôtelier, de 1958 à 1962, que la construction de chalets a été la plus intense: 40 immeubles mis à l'enquête en 1961. Actuellement on compte entre 300 et 400 chalets à louer, mais sur le nombre de locataires les chiffres manquent. Une estimation faite d'après les taxes de séjour perçues par l'Office du tourisme donne pour le mois de décembre 1966 enivron 12400 nuitées et la durée moyenne de séjour serait de trois semaines, soit trois fois plus que dans les hôtels.

Depuis quelques années une formule a fait son apparition: l'immeuble à appartements en copropriété. Cette institution ne possède ni les avantages du chalet - être chez soi — ni ceux de l'hôtel - 
le service - et son succès semble provenir d'un intérêt financier plutôt que touristique.

Le développement des chalets a profité aux paysans qui ont pu vendre du terrain et aux commerçants en produits alimentaires qui peuvent livrer au détail. D'une manière générale le commerce est florissant et deux banques ont ouvert une succursale à Villars. Quant aux hôteliers, ils ne désespèrent pas. Ils comptent que la propagande faite par les locataires de chalet attirera également les habitués du séjour en hôtel. Ils cherchent avant tout à élargir la renommée de Villars et à multiplier les innovations en matière de sport et de divertissements.

Villars, et plus spécialement ses "faubourgs» Chesières et Arveyes, se sont spécialisés dans une branche annexe du tourisme: les maisons d'enfants. Ce terme englobe des institutions variées:

- Les homes pour enfants d'un mois à 6 ans, tenus par des infirmières.

- Les maisons qui prennent en charge pendant les vacances un nombre restreint d'enfants de 3 à 16 ans et organisent leurs loisirs.

- Les instituts, véritables écoles ou lycées privés, qui selon le slogan «étude, santé, sport" réservent la moitié de la journée aux exercices physiques. Les élèves peuvent $\mathrm{y}$ atteindre le nombre de 200 .

La clientèle des maisons d'enfants est étrangère en grande majorité, surtout français et belge pour les raisons linguistiques évidentes.

Pourquoi ces maisons d'enfants pullulent-elles à Villars-Chesières alors que d'autres stations de montagne n'en comptent que peu? Le climat excellent et les nombreuses forêts propices aux jeux d'enfants ne suffisent pas à expliquer cette disproportion. Malheureusement nous ignorons tout des premières maisons d'enfants construites au début du siècle. Mais comme Villars comptait déjà à cette époque plus d'établissements de luxe que de pensions de famille, on peut supposer que les clients de ces hôtels confiaient leurs enfants pendant leur séjour à des personnes patentées: nurses, infirmières, etc. Plus tard, lorsque les homes de Villars eurent atteint un certain renom, les enfants y furent envoyés seuls ou en colonie de vacances, mais les parents venant les visiter logeaient à l'hôtel. Ainsi maisons d'enfants et hôtels ont toujours eu des intérêts communs. Beaucoup de pensions ont été transformées en homes et vice versa. Vers 1929 une loi interdisant la construction de nouveaux hôtels provoqua l'ouverture d'une trentaine de homes en sept ans ${ }^{49}$. Depuis quelques années une tendance à la concentration se manifeste:

$\begin{array}{rrr}1942- & 1961- & 1966- \\ 1943 & 1962 & 1967 \\ 24 & 32 & 26 \\ 429 & 750 & 805\end{array}$

Les petits homes subissent les répercussions de la crise hôtelière bien qu'ils aient un avantage: leur taux d'occupation ne dépend pas du temps et ils sont surs d'être pleins au moins durant les vacances d'été. Les grands instituts en revanche maintiennent leurs positions car ils fonctionnent l'année entière.

\section{Tourisme et population}

Le tourisme a créé à Villars de nombreux emplois et causé un afflux de population étrangère avant tout. Il est bien connu que le tourisme compense l'industrie là où elle fait défaut et "draine le pouvoir d'achat des villes vers les zones économiquement sous-développées» $\mathbf{5 0}$.

Mais on considère également que "par sa capacité d'emploi il empêche l'exode rural»51. Or tel n'a pas été le cas de Villars.

Il est évident que le terme "exode rural» ne signifie pas seulement renoncement à l'activité paysanne, car la diminution des entreprises agricoles en montagne est inévitable, d'autant plus dans une station touristique où les modes de vie traditionnels se perdent vite au contact des villégiants. Une étude faite à Chesières pendant la guerre montre comment dans une petite exploitation les frais d'entreprise et les intérêts des dettes ne laissent qu'une marge de bénéfice insignifiante, ceci en dépit du débauché avantageux pour le lait que représente la station 52 . D'autre part un paysan ne se résoudra à vendre du terrain que s'il envisage d'abandonner la campagne. Aussi prévoit-on que d'ici dix ans, il ne subsistera dans tout Villars-Chesières-Arveyes qu'une ou deux exploitations agricoles.

Il semblerait logique que les jeunes qui renoncent à la campagne trouvent un emploi sur place dans le secteur secondaire ou tertiaire. Ainsi le font les fils d'artisans, en particulier les maçons et charpentiers que la construction de chalets occupe tout l'été, alors qu'en hiver ils sont généralement professeurs de ski (parfois même ils ont pu ouvrir une pension ou un home d'enfants). Les fils de paysans cependant vont s'établir en ville: il y a réellement exode rural, camouflé par l'augmentation massive de gens venus du dehors.

Chiffrer l'empleur de l'émigration est impossible ${ }^{53}$. Mais dans le secteur Villars-Chesières-ArveyesHuémoz, le total de la population vaudoise a luimême diminué, passant de 883 en 1954 à 825 en 1966.

Les causes de l'émigration sont les suivantes:

— Les emplois à Villars, ceux de l'hôtellerie surtout, sont saisonniers; la morte-saison entraîne un véritable chômage. Aussi le personnel des hôtels est-il très mobile. Si les emplois subalternes sont occupés 
par les saisonniers étrangers, même les portiers et cuisiniers - en général Valaisans ou Suisses allemands - se déplacent au cours de l'année entre Villars et des stations de plaine telles que Montreux, Locarno ou Genève.

- Les activités indépendantes dans le commerce ou dans l'hôtellerie, dont les revenus pendant la saison suffisent à compenser les pertes de l'entresaison, exigent au départ un capital liquide qu'un fils de paysan endetté ne peut guère se procurer. Comme en plaine, ce sont pour la plupart des Confédérés ou des Italiens qui ont pris des initiatives et qui se trouvent maintenant à la tête de pensions ou de commerces florissants.

- Enfin il ne faut pas négliger les causes psychologiques. Le paysan n'a pas su s'adapter au tourisme ${ }^{54}$. Patron de son exploitation, l'idée de servir la clientèle lui répugne. Il se sent dépaysé à la station, et s'il abandonne la campagne, rien ne l'y retient. Même les jeunes qui vont en apprentissage à l'extérieur préfèrent s'établir là où ils se trouvent.

Ainsi le tourisme n'a pas favorisé le développement démographique naturel: il a accéléré l'exode de la population autochtone et l'a remplacée par une société nouvelle et multinationale. Cela a valu à Villars-Chesières son essor économique extraordinaire, mais également un isolement radical par rapport au reste de la commune demeuré agricole et indigène.

La zone des Mi-Monts a conservé une vie ancestrale, n'ayant pu profiter ni des atouts de la plaine ni de ceux de la montagne.

Si le climat y est encore moins rude qu'à VillarsChesières, la chaleur de l'été et la rareté de la neige en hiver ont empêché l'implantation du tourisme de montagne. De point de vue agricole, si les cultures sont possibles à cette altitude, les Mi-Monts sont défavorisés - même par rapport à Villars — sous trois aspects:

- Les sols sont en général pauvres et secs, le gypse affleure même par endroits.

- La raideur de la pente rend le travail très pénible, limite le nombre de dévestitures et le degré de motorisation. Un dicton affirme: Mieux vaut être bœuf à Chesières que femme à Huémoz ${ }^{55}$.

- Le morcellement est intense et tous les essais de remaniements ont échoué.

En dépit des primes accordées par la Confédération, les cultures se sont réduites à quelques champs de pomme de terre pour l'usage personnel. Les MiMonts vivent surtout du bétail. La majorité des propriétaires possèdent des "basses montagnes» et font estiver leur bétail - à l'exception de quelques laitières - sur les communaux. Ils ont gardé l'habitude des déplacements, descendent en plaine pour la culture de leurs vignes et parfois même remuent entre des étables situées au même niveau.

La production laitière procure un revenu régulier mais insuffisant. Huémoz réussit depuis peu à livrer le lait à Villars pendant la saison touristique d'hiver exclusivement. Pour le reste, les habitants des MiMonts, situés en dehors des circuits de ramassage laitier, doivent se contenter de vendre la crème et se ratrappent en engraissant des porcs. Quelques-uns, profitant de la forte demande, engraissent également des veaux de leur étable, mais l'activité par excellence du montagnard reste l'élevage. Elle se heurte cependant à de nombreuses difficultés depuis qu'elle a cessé d'être un monopole 56 .

En effet l'extension des cultures pendant la guerre et l'introduction des silos a prouvé au paysan de plaine que son cheptel ne devait pas nécessairement être proportionnel à ses surfaces herbagères et l'a incité à pratiquer l'élevage lui-même. En plus la qualité du bétail de montagne paraît baisser pour deux raisons:

- L'existence en montagne de subsides à l'élimination de bétail inapte pousse le montagnard à élever tous ses vœux sans discernement: s'il ne peut les vendre, il est certain d'en tirer un bénéfice à la boucherie.

- Depuis que les marchands de bétail achètent sur place, les meilleures productrices tendent à disparaître des étables, achetées au prix fort. (Autrefois le paysan n'emmenait à la foire que les bêtes qu'il destinait à la vente.)

D'ailleurs les montagnes d'Ollon n'ont pas une tradition d'élevage solidement établie et ne se livrent que peu à l'élevage des taureaux. L'introduction de l'insémination artificielle ne les désavantagerait pas. Au contraire, si cette innovation pouvait être réservée aux montagnards, ils pourraient peut-être, au prix d'une certaine discipline dans le cadre des syndicats existants, retrouver le monopole de l'élevage par la qualité.

Depuis quelques années la culture de la framboise et du cassis se répand, de même que celle des plantons de fraises sans virus: les plantons de montagne sont en effet insensibles au virus qui infeste les cultures de plaine. Toutes ces plantes exigent un travail soigné et beaucoup de main-d'œuvre lors de la cueillette, mais leur rentabilité ne fait pas de doute.

Les tentatives de développer l'industrie à domicile entreprises après la guerre dans le cadre de l'aide aux montagnards, n'ont pas abouti, mais pendant la saison d'hiver quelques habitants des Mi-Monts trouvent un emploi sur les téléskis de Bretaye (11 personnes, dont 8 paysans) ou comme bûcherons saisonniers. Une demi-douzaine de bûcherons de Panex travaillent à plein temps.

Actuellement l'agriculture ne se maintient que grâce aux nombreuses subventions (subsides pour achat 
de machines, pour garde ou élimination de bétail, pour achat de taureaux, pour vente de veaux à des engraisseurs de plaine, etc. ${ }^{57}$. Mais le principe même du subventionnement ne satisfait pas tous les paysans. Certains ont atteint une certaine aisance en vendant des parcelles qu'ils possédaient à Villars. Mais d'une manière générale l'économie agricole des Mi-Monts est plus viable que rentable.

$\mathrm{Vu}$ les conditions économiques il n'est pas étonnant que les Mi-Monts se dépeuplent: les jeunes apprennent un métier et émigrent. Nous avons vu que Huémoz fait exception en devenant en quelque sorte la banlieue de Villars-Chesières. Le nombre d'indigènes qui ont trouvé un emploi fixe à la station est certes faible ( 6 personnes), mais quelques femmes ou filles de paysans y travaillent à l'occasion comme femme de ménage ou à Bretaye comme sommelière en hiver. On trouve à Huémoz également une pension à clientèle suisse romande.

Dans l'ensemble des Mi-Monts, cette nouvelle forme de tourisme qu'est la villégiature en chalet, sans arrêter le dépeuplement, procure un certain bienêtre à ceux qui restent. Elle peut adopter trois formes:

- Location de maisons habitées, ceci en été pendant que les propritétaires remuent. On connaît quelques cas à Panex-Plambuit.

- Achat de maisons anciennes que le nouveau propriétaire, amateur de calme et de rusticité, rénove plus ou moins. Ce type est répandu à Pallueyres et dans le dizain de Panex, c'est-à-dire à l'écart des grandes routes.

- Construction de nouveaux chalets pour le weekend et les vacances qui foisonnent un peu partout, en particulier dans les zones basses (Antagnes, plateau de Glutières): là ils se mêlent aux villas habitées toute l'année.

Les Mi-Monts tendent à imiter à la fois la station touristique et la zone résidentielle de la plaine. Mais cette synthèse ne paraît guère apte à résoudre leurs problèmes. Elle n'a d'autre avantage que de permettre aux paysans de réaliser une partie de leur capital foncier, encore que la loi Vouga, qui en zone agricole n'autorise à construire que sur une parcelle d'au minimum 45 ares, les défavorise. Comme le prix du terrain en pente reste relativement bas, les acheteurs ne se laissent pas décourager par les exigences de la loi, mais le paysan se voit contraint à vendre plus qu'il ne désire. Aussi des plans d'extension sont-ils prévus pour Antagnes, Glutières et Panex. Mais la construction ne crée pas de nouvelles activités. Il n'y a pas d'entreprises de construction sur place et les villégiants font leurs achats à Ollon ou à Villars. Zone marginale entre ces deux pôles d'attraction, les Mi-Monts semblent condamnés à végéter.

\section{Historique}

La comumne d'Ollon, constituée déjà au $\mathrm{XIV}^{\mathrm{e}}$ siècle ${ }^{58}$, devint sous le régime bernois une véritable unité politique nommée "mandement».

Le mandement, parfois pompeusement appelé «république d'Ollon", était une véritable confédération. Il y avait 6 dizains en plaine (les 4 quartiers d'Ollon, Saint-Triphon et Antagnes) et 6 en montagne. Chacun avait son conseil des chefs de famille, sa bourse, sa fontaine, sa pinte et quelques bien-fonds. Ils étaient responsables de la police rurale, de l'entretien des eaux et de l'enseignement. Seuls les dizains étaient compétents pour l'admission de nouveaux bourgeois 59 .

En 1803 la commune se substitua au mandement. Alors que tant de petites localités du canton s'érigèrent en communes autonomes, les dizains d'Ollon ne tentèrent pas de se rendre indépendants. Trop de liens économiques les unissaient. En revanché leur autonomie fut progressivemnt réduite et disparut définitivement en 1874. Mais encore actuellement on cherche à représenter équitablement les différents dizains au conseil communal et souvent les municipaux qui ne sont pas du cheflieu jouent un peu le rôle de syndic dans leur dizain 60 .

Plus que la division juridique en dizains, l'opposition entre la plaine et la montagne s'est manifestée par une forte rivalité et ceci dès le XVIII ${ }^{\mathbf{e}}$ siècle, ainsi que l'attestent des procès entre les deux parties. Longtemps la commune compta deux syndics et deux boursiers, puis on attribua alternativement ces deux fonctions à des gens de la plaine et de la montagne ${ }^{61}$. Au début du XIX ${ }^{\mathrm{e}}$ siècle la montagne pensa sérieusement à se rendre autonome, mais les parties ne purent s'entendre sur le partage des alpages communaux ${ }^{62}$. D'ailleurs les gens de la plaine, majoritaires, avaient plus de propriétés en montagne que les montagnards en plaine: ils refusèrent toute sécession lors d'un vote en 1823 . La création d'une paroisse à Huémoz, chef-lieu de la montagne, vint appaiser le conflit63. Dès lors il ne fut plus officiellement question de partage.

Quelle est actuellement la situation des domaines communaux qui ont assuré la cohésion de la commune?

\section{Pâturages et forêts}

La plupart des alpages ne sont plus des "communs", car la municipalité ayant racheté les chalets préfère les louer à des amodiateurs pour un loyer fixe indépendant du nombre de bétail. Dans ces conditions l'exploitation devrait être plus intensive64, néanmoins depuis la guerre la grandeur des troupeaux diminue, car la main-d'œuvre étant trop chère 
l'amodiateur doit généralement se passer d'aide. La fabrication de fromage ne se pratique plus sur les alpages, d'une part par manque de fromagers, d'autre part parceque certaines alpes peuvent livrer leur lait à Villars, fort consommateur pendant la saison touristique d'été. Bretaye, desservi par le chemin de fer, est particulièrement favorisé à cet égard.

En dépit de cet avantage les hautes montagnes sont en déclin. Les montagnards préfèrent désormais faire estiver leur bétail sur les basses montagnes, plus proches de la station touristique, et les paysans de plaine n'envoient en montagne que les genisses. Les alpages n'ont pas été améliorés: les chemins et les bâtiments rationnels font défaut, les nombreux marécages sont mal drainés. En 1965 les alpages ont rapporté à la bourse communale un bénéfice de 5550 francs contre près de 12000 francs en 1942.

Le domaine forestier est plus rentable. Il tend même à s'arrondir par reboisement: on projette la création de rideaux d'arbres en plaine et la transformation des vernaies du bord du Rhône en plantation de noyers et de peupliers.

Néanmoins l'exploitation des bois est fortement entravée dans les forêts communales par la rareté et le mauvais état des chemins. Longtemps les investissements ont fait défaut et les nouveaux projets ne sont pas encore mis en chantier. L'Etat a entrepris des travaux, mais en restant strictement sur son domaine et la commune ne peut en porfiter.

Depuis que le travail du bûcheron est permanent le recrutement de la main-d'œuvre est problématique. La commune emploie une douzaine d'ouvriers qui doivent cependant consacrer environ deux mois par an à l'entretien des alpages.

Les coupes s'élèvent à environ $2000 \mathrm{~m}^{3}$ par an (plus $1000 \mathrm{~m}^{3}$ dans les forêts de l'Etat). Le bois de hêtre (un quart du total) est vendu comme bois de feu aux particuliers et aux services communaux. Le bois d'œuvre trouve un débouché sur place chez les constructeurs de chalets qui en prennent la moitié. Indépendants des frais de transport, les prix du marché régional sont plus élevés que les cours cantonaux. Les scieries locales sont cependant obligées d'importer de longues pièces du Jura, car le manque de chemins ne permet pas aux bûcherons d'Ollon de sortir les grumes entières. Ainsi par un défaut d'infrastructure la commune ne profite qu'à moitié d'un débouché créé par le tourisme et doit abandonner une partie de ses billons à l'Association forestière vaudoise. Quant au bois d'industrie autrefois destiné à la papéterie, il est actuellement livré à la fabrique de «bois homogènes» de Saint-Maurice.

Bien que les prix aient baissé après l'ouragan de 1963, l'exploitation des bois est toujours rentable; mais elle ne constitue plus, comme il y a quarante ans, le principal revenu de la bourse communale. Le bénéfice - 51000 francs en 1965 — n'est pas très considérable, mais en revanche il ne varie guère d'une année à l'autre.

\section{Rapports actuels à l'intérieur de la commune}

A l'ancienne rivalité plaine - montagne s'est substituée depuis cinquante ans une opposition entre la station touristique et l'ensemble de la zone paysanne.

Le tourisme n'apporte rien aux paysans de la plaine. Les hôtels et commerce se ravitaillent en gros à Vevey ou Lausanne, leur seul fournisseur à Ollon étant l'Association viticole. Le chemin de fer a longtemps orienté Villars vers Bex, la motorisation a cependant facilité les rapports avec le chef-lieu. Avant tout l'afflux de population étrangère à Villars a suscité la méfiance des gens de plaine, alors que les promoteurs entreprenants de la station sont peu portés à comprendre le conservatisme paysan. Aussi l'idée de partager la commune a-t-elle reconquis quelques adeptes aussi bien en plaine qu'en montagne. Les griefs réciproques portent surtout sur la répartition des recettes et dépenses communales. Le bas se plaint de trop payer, le haut de ne pas assez recevoir, mais évidemment aucun chiffre ne permet de vérifier le bien-fondé de ces assertions. On peut toutefois supposer que la station bénéficie plus largement des travaux entrepris par la commune, mais il est à peu près certain qu'elle paye plus d'impôts; d'autre part les droits de mutation perçus lors du transfert de propriétés, qui fournissent une part appréciable des recettes, proviennent surtout de Villars-Chesières. Ainsi il est probable qu'une certaine équité règne dans les finances communales. Au niveau des autorités les rapports sont bons et les dépenses pour la montagne sont généralement acceptées sans amendement par les délégués de la plaine. La répartition politique des sièges au conseil communal reflète les activités très variées des électeurs: 24 radicaux, 21 socialistes, 17 agrariens et 8 libéraux.

Le syndic est toujours un homme de la plaine, mais la station fournit trois conseillers municipaux sur sept, proportion qui correspond assez à celle de la population: 1800 sur 4100 . Une certaine tradition fédéraliste héritée du passé permet aux autorités d'administrer ensemble deux zones qui ont perdu tout intérêt commun.

\section{Conclusion}

Conformément à sa position géographique la commune d'Ollon a longtemps pratiqué une économie de versant polyvalente et un genre de vie qui ressemble déjà beaucoup à celui du Valais. Comme en Valais la conquête des fonds de vallée et l'essor du 
tourisme ont bouleversé l'économie traditionnelle: plaine et montagne se sont spécialisées en suivant des voies divergentes.

La plaine, joignant l'initiative des immigrés à la prudence des indigènes, progresse lentement vers une modernisation de l'agriculture. Sur le replat de Villars-Chesières l'évolution a été plus rapide, mais au prix d'une véritable transfusion de population. La spécialisation s'est développée à un tel point qu'Ollon et Villars sont actuellement deux mondes étrangers l'un à l'autre, qu'unit seul un lien administratif. Si la fonction d'une commune est de grouper des intérêts convergents, alors un partage s'impose; si au contraire elle doit établir un certain équilibre entre des secteurs complémentaires, alors l'unité de la commune d'Ollon est justifiée.

Mais le problème principal, le problème de la pente, n'a pas été résolu. Le déclin économique des $\mathrm{Mi}$ Monts en témoigne. L'économie actuelle tend à concentrer les activités sur les terrains planes, ne réservant à la pente qu'une fonction résidentielle. Ce phénomène si fréquent dans les agglomérations urbaines se répète ici sur un vaste territoire.

\section{Documents}

1 Archives communales d'Ollon (non-classées) .

2 Statistiques fédérales de la Suisse, Berne.

- Recensements de la population;

- Recensements des entreprises;

- Statistiques des cultures;

- Recensements du cheptel;

- Annuaire statistique de la Suisse, chapitre tourisme.

3 La Vie économique, $380^{\circ}$ à $400^{\circ}$ année, Genève 1965-1967.

4 Prospectus touristiques de Villars-Chesières.

\section{Manuscrits}

5 F. Isabel: Les Alpes d'Ollon, étude d'histoire locale 1901, chez M. J. Isabel, Chesières.

6 W. Bischoff: Untersuchungen auf landwirtschaftlichen Betrieben in den Waadtländer Alpen (Gemeinde Ollon), Zurich 1944. Geographisches Institut Zürich.

7 J. Dubois: Etude statistique de l'agriculture vaudoise $1^{\text {re }}$ partie: Le Chablais vaudois, 1967. Bureau de l'aménagement régional, Lausanne.

\section{Livres et articles}

8 H. Badoux: La géologie des collines de Saint-Triphon. Bull. des laboratoires de géol. de Lausanne, $\mathrm{n}^{\circ} 133,1962$.

9 A. Barman: Villars 1866-1966, plaquette Office du tourisme de Villars, 1966.
10 C. Biermann: La maison paysanne vaudoise. Lausanne 1946.

11 L. Bridel: L'agriculture de la cluse alpestre du Rhône. Revue de géographie de Lyon, 1958.

12 L. Bridel: Les améliorations foncières dans la plaine du Rhône. Revue technique suisse de mensuration, $1959, \mathrm{n}^{\circ} 1$, p. 16 à 27.

13 C. Buhrer: Le climat du canton de Vaud. Bull. de la Soc. vaudoise de sciences nat., vol. XXXII, $\mathrm{N}^{\circ} 122$ (1896).

14 C. Bürky: Die Siedlungen des Rhonequertales in ihrer Abhängigkeit von den Formenelementen des Tales, thèse, Leipzig 1911.

15 Commission extraparlementaire pour l'étude du tourisme: Le tourisme vaudois et son apport économique. («Rapport Tissot»), Lausanne 1966.

16 J. Dubois: Le vigneron vaudois et ses vins, thèse, Lausanne 1944.

17 E. Gagnebin: Les invasions glaciaires dans le bassin du Léman. Bull. des laboratoires de géologie de Lausanne, $\mathrm{N}^{\circ}$ 58, 1937.

18 B. Hasselrot: Etude sur le dialecte d'Ollon, thèse, Upsal 1937 (v. Introduction géogr. et historique).

19 M. Lugeon: Notice explicative à la feuille 19 de l'atlas géologique suisse. Berne 1940.

20 M. Lugeon, E. Gagnebin: Observations et vues nouvelles sur la géologie des préalpes romandes. Bull. des laboratoires de géologie de Lausanne, $\mathbf{N}^{\circ}$ 72, 1941.

21 F. Maillard: Notice sur Ollon, Lausanne 1870.

22 H. Onde: La cluse alpestre du Rhône, le coude de Martigny et l'X valaisan. Mélanges géographiques offerts à Ph. Arbos, Clermont-Ferrand 1953.

23 P. Régamey: Améliorations foncières dans la plaine vaudoise du Rhône. Revue technique suisse de mensuration 1955, $\mathrm{N}^{\circ} 5$, p. 114 à 126.

24 P. Veyret: Modernisation de la vie montagnarde en Suisse. Revue de géographie alpine, tome XXXVII, fasc. 3), 1949.

\section{Zusammenfassung}

Ihrer Lage und Ausdehnung entsprechend hat die Gemeinde Ollon, deren Entwicklung die vorliegende Studie untersucht, während langer Zeit ein Leben geführt, das sich auf einem mehrstufigen Wirtschaftssystem aufbaute und in mancher Beziehung jenem gewisser Walliser Gemeinden glich. Wie im Wallis haben sich indessen die Betriebe im Rhonetal und jene in den Bergzonen in divergierender Weise spezialisiert. Sie gehen heute durchaus verschiedene Wege. Während in der Rhoneebene Einheimische wie Zugezogene auf eine allmähliche Modernisierung der Landwirtschaft hinarbeiten, hat sich auf der Terrasse von Villars-Chesières infolge 
der raschen Expansion des Fremdenverkehrs eine vollkommene Umstellung ergeben, welche Ollon und Villars in der Gegenwart als einander gänzlich fremde, nur administrativ, im Gemeindeverband verknüpfte Welten erscheinen läßt.

\section{Remarques}

1 Bibliographie 14: Bürky, p. 175, 192-193.

2 Bibliographie 10: Biermann, p. 60-61.

3 Bibliographie 10: Biermann, p. 196.

4 E. Mottaz: Dictionnaire historique du canton de Vaud, Lausanne 1915.

5 Bibliographie 2: Stat. féd. Recens. pop.1960, fasc. communes d'orig. (S 387).

6 Bibliographie 11: Bridel, p. 167.

7 En 1930 déjà on comptait 659 Bernois, mais seule. ment 241 personnes nées dans le canton de Berne.

8 Bibliographie 2: Stat. féd.

9 Bibliographie 2: Stat. féd. Recens. pop. 1960, fasc. Migrations alternantes. S. 383.

10 Bibliographie 21: Maillard, p. 42.

11 Bibliographie 21: Maillard, p. 29.

12 Ph. S. Bridel: Essai statistique sur le canton de Vaud. Lausanne 1815.

13 Bibliographie 14: Bürky, p. 102-103.

14 Bibliographie 21: Maillard, p. 29.

15 Bibliographie 5: Isabel.

16 Abstraction faite des alpages et des forêts. Il s'agit naturellement de parcelles d'exploitation et non de parcelles cadastrales qui atteignent facilement la centaine.

17 Bibliographie 2: Stat. féd. - Recens. des entreprises.

18 Bibliographie 5: Isabel.

19 Mémoire des communes d'Aigle, Bex, etc. ... sur l'expropriation... de leurs forêts. Lausanne 1831.

20 Bibliographie 6: Bischoff.

21 Bibliographie 6: Bischoff.

22 Bibliographie 23: Régamey, p. 118 à 120.

23 Bibliographie 1: Archives.

24 Bibliographie 7: Dubois, p. 5.

25 Rendement moyen 1953 à 1960: 423 qx/ha.

District d'Orbe 396 qx/ha; district de Payerne 448 $\mathrm{qx} /$ ha (chiffres d'Aarberg).

26 Chiffres du Bureau d'aménagement régional.

27 Bibliographie 11: Bridel, p. 167.

28 Bibliographie 2: Stat. féd. Recens. des entrep.

29 Bibliographie 12: Bridel, p. 24.

30 Bibliographie 11: Bridel, p. 167.

31 En 1946 une "entreprise viticole moyenne» comprenait 200 a (d'après O. Howald, Einführung in die Agrarpolitik. Berne 1946).

32 Bibliographie 16: Dubois, p. 39.

33 Bibliographie 16: Dubois, p. 31.

34 Bibliographie 16: Dubois, p. 45.
35 Bibliographie 16: Dubois, p. 110.

36 Bibliographie 14: Bürky, p. 89.

37 Bibliographie 21: Maillard, p. 13.

38 Bibliographie 2: Stat. féd. - Recens. pop. 1960, fasc. migrations alternantes, S 383 .

39 voir carte $\mathrm{N}^{\circ} 6$ «Communications et mouvements pendulaires».

42 Bibliographie 5: Isabel.

43 Bibliographie 9: Barman.

44 Voir en annexe calque "Tourisme et construction".

45 P. Defert: L'avenir touristique du bassin du Léman. "Service - Direction», juin 1960, Paris, p. 709.

46 Bibliographie 15: Rapport Tissot.

47915 personnes non résidentes dans la commune possèdent des terrains sur le territoire d'Ollon, dont 138 seulement habitent le district d'Aigle, 214 le district de Vevey, 295 l'agglomération lausannoise, 128 le canton de Genève et 124 l'étranger.

De 1961 à 1964 les personnes domiciliées à l'étranger ont acquis $240000 \mathrm{~m}^{2}$ pour une valeur de 12 millions de francs (d'après Bibliographie 3 la Vie économique, 1965 , p. 442).

49 Bibliographie 1: Archives.

50 Bibliographie 15: Rapport Tissot.

51 Bibliographie 15: Rapport Tissot.

52 Bibliographie 6 ; Bischoff.

53 Même une fiche de police ne permet pas d'identifier qui est indigène, la meilleure définition de l'indigène étant: celui qui a passé sa jeunesse sur place. Si cependant on ne compte que les Vaudois nés à Villars-Chesières (or beaucoup d'indigènes sont d'origine bernoise, et ont gardé leur bourgeoisie) on recense dans cette catégorie, pour la période de 1958 à 1963, le départ définitif de 49 personnes actives, surtout en direction de Vevey, Lausanne, Yverdon et Genève. D'autre part, parmi quelque 800 abonnés au téléphone, seuls 15 nonpaysans sont de souche paysanne indigène. Parmi ceux-ci on note plusieurs entrepreneurs et camionneurs.

54 Bibliographie 24: Veyret, p. 410.

55 Bibliographie 5: Isabel.

56 Bibliographie 24: Veyret, p. 394.

57 Pour la garde de bétail uniquement, les subsides s'approchent du chiffre de 90000 francs par an.

58 Bibliographie 18: Hasselrot, p. 13.

59 Bibliographie 5: Isabel, repris par 18 Hasselrot.

60 Pour l'enseignement les dizains ont été sacrifiés. Le nombre de collèges a été réduit de 9 à 5 et il est question d'amener tous les élèves des Mi-Monts à Ollon.

61 Bibliographie 5: Isabel.

62 Bibliographie 21: Maillard, p. 18.

63 Bibliographie 5: Isabel, repris par 18 Hasselrot, p. 14.

64 Bibliographie 6: Bischoff. 